\title{
Induced selectivity in the photochemistry of estrone derivatives in sustainable and micellar environment: preparative and mechanistic studies
}

\author{
Matías I. Quindt ${ }^{1,2} \cdot$ Gabriel F. Gola $^{1,3} \cdot$ J. A. Ramirez ${ }^{1,3} \cdot$ Sergio M. Bonesi ${ }^{1,2} \mathbb{D}$
}

Received: 14 July 2021 / Accepted: 16 September 2021 / Published online: 1 October 2021

(c) The Author(s), under exclusive licence to European Photochemistry Association, European Society for Photobiology 2021

\begin{abstract}
In this study, we carried out preparative and mechanistic studies on the photochemical reaction of a series of 3-acylestrone derivatives in confined and sustainable micellar environment under steady-state conditions and the results were compared with those obtained in cyclohexane solution. The aim of this work is mainly focused to show whether the nature of the surfactant (cationic, neutral and anionic) leads to noticeable selectivity in the photoproduct formation. The 3-acylestrone derivatives underwent the photo-Fries rearrangement, with concomitant homolytic fragmentation of the ester group and [1;3]-acyl migration. This pathway afforded the ortho-acyl estrone derivatives, the main photoproducts together with estrone. However, epimerization of the ortho regioisomer 2-acetylestrone and estrone through Norrish Type I photoreaction occurred involving the fragmentation of the C- $\alpha$ at the carbonyl group (C-17) of the steroid. UV-visible and 2D-NMR (NOESY) spectroscopies have been employed to measure the binding constant $\mathrm{K}_{\mathrm{b}}$ and the location of the steroids within the hydrophobic core of the micelle.
\end{abstract}

\section{Graphic abstract}

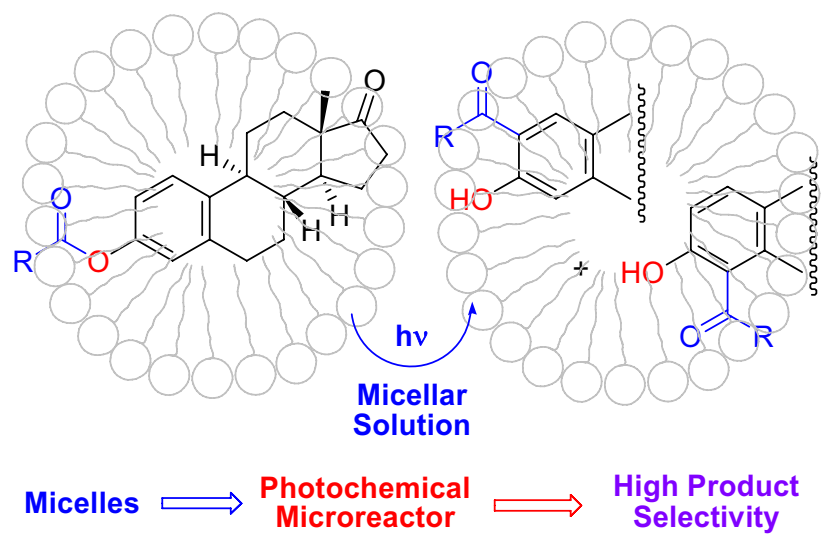

\section{Introduction}

The past decades have witnessed a rapid development of the photochemistry of steroids which is a challenging topic that produces continuous reports in both academic and industrial area. Indeed, recently reports on the

Sergio M. Bonesi

smbonesi@qo.fcen.uba.ar

Extended author information available on the last page of the article photodegradation of some steroidal hormones in aquatic environments performing the irradiation under direct or photosensitized procedures have been studied [1-5]. For example, the photodegradation of $17 \beta$-estradiol (E2), an endocrine-disrupting hormone was investigated in wastewater effluents at different $\mathrm{pH}$ values under simulated solar irradiation employing effluent organic matters (EfOM) as triplet photosensitizers [1]. Likewise, the degradation of E2 and estriol E3, which is an steroidal hormone, was 
investigated under direct UVC (254 nm) light in the presence of oxidants additives, such as $\mathrm{H}_{2} \mathrm{O}_{2}$ or $\mathrm{O}_{3}$ and alternatively, in the presence of photocatalyst $\mathrm{TiO}_{2}$ to evaluate the possible degradation in a natural surface water matrix $[2,3]$. Furthermore, the photoinduced degradation of an estrogen derivative, such as $17 \alpha$-ethinylestradiol (EE2) has been studied in detail in terms of kinetic and mechanistic viewpoints using aquatic humic acid and fulvic acid solutions simulating natural water matrixes [4]. The photodegradation by solar light of glucocorticoids in freshwater have been reported and it was found that the photoproducts are environmental toxic compounds as was assessed by $V$. fischeri and P. subcapitata inhibition assays [5]. The effect of solar UV light on anti-inflammatory corticosteroids dexamethasone, prednisone and prednisolone in water and in micellar solutions under different atmospheric conditions has been studied in terms of kinetic, mechanistic and toxicological aspects [6]. Light-induced degradation of steroid hormones, such as testosterone and androstenedione was also studied from a mechanistic viewpoint and a detailed characterization of the photoproducts were carried out [7-9]

The photochemical behavior of steroids in solution was completely studied in terms of photorearrangement, photoaddition, photoreduction and photooxidation reactions throughout the years [10] and photochemical approaches toward the synthesis of natural products have been applied with success [11]. Some recent examples regarding the photochemistry of steroids have been reported. Thus, the photochemistry of trenbolone acetate metabolites have been studied in aqueous solutions in the presence of sodium azide, thiosulfate or ammonia and direct incorporation of these nucleophiles across the trienone moiety present in the steroid substrates [12]. Regioselective photoinduced incorporation of fluorine atom of acetonide ketal moieties that are present in steroids has been developed. In fact, photosentization of steroids with xanthone in the presence of Selectfluor as the fluorine source provided the fluorinated photoproducts in good yields [13]. Late-stage dehydrogenative amination using ammonia to give free anilines under photocatalytic conditions was successfully applied on the A ring of the birth-control medicine levonorgestrel and estra-5,9-diene3,17-dione, respectively, providing the corresponding anilines in 84 and $82 \%$ yield. The photoreaction involves the use of iridium and cobalt complexes as the visible photocatalysts and blue LEDs as the visible light source [14]. Likewise, a ruthenium photoredox catalyst $\mathrm{Ru}(\mathrm{bpy})_{3}(\mathrm{BF} 4)_{2}$ was successfully applied in the preparation of 18-nor-17 $\beta$ hydroxymethyl-17 $\alpha$-methylandrost-13-ene unit which is found in long-term metabolites of 17-methylated androgenic anabolic steroids (AAS) [15]. The photochemical reaction involves a smooth dicarboxylative alkynylation and reacting regiostereoselectively with a phenylacetylene derivative at
C-17 providing the photoproducts with a 2.7:1 diastereoselectivity in favor of steroid derivative with $S$ configuration at C-17.

Along the past years, some interesting examples of the photochemistry of steroids have been studied in terms of preparative, mechanistic and analyzing the stereospecificity of the photoreaction [16-21]. Indeed, photoinduced lactonization reaction of some cholestan-6-one derivatives provided efficiently 6-oxa-B-homocholestan-7-ones with retention of the configuration at C-5 [16]. Likewise, direct irradiation of $3 \alpha$-(dimethylphenylsilyloxy)-5 $\alpha$-androstane-6,17-dione and its $3 \beta$ isomer gave two distinct photoproducts arising from the photoreduction and the Norrish type I reactions of the steroids. An antenna-photosensitization process from the arylsilyloxy group to the carbonyl groups through triplet and singlet energy transfers accounts for this particular behavior [18]. The photo-Fries rearrangement of some 3 -acylestrone in homogeneous media was studied in detail covering the preparative and mechanistic aspects of the photoreaction [22]. The ortho-regioisomers were obtained in good yields along with the corresponding estrone. Photosensitization with acetone has demonstrated that the photoreaction involves the singlet excited state as the photo reactive state. Likewise, the photochemical behavior of some estrone aryl and methyl sulfonates in solution was carried out under direct UV (254 nm) irradiation and [1;3]-sulfonyl migration was the main photochemical pathway providing the orthosulfonyl estrone derivatives and estrone as the photoproducts [23].

On the other hand, photochemical microfluidic strategy has been recently developed and its application in photochemical synthesis of steroidal intermediates has been satisfactorily achieved [24-26]. A low-pressure lamp with a LB-PDMS composite film was successfully employed in the photochemical synthesis of $9 \beta, 10 \alpha-3,20$ bis(ethylenedioxy)-5,7-pregnadiene (L-BEP) from $9 \alpha, 10 \beta$ 3,20-bis(ethylenedioxy)-5,7-pregnadiene (E-BEP) which was chosen as the model substrate to assess the improved UVB light [24]. Likewise, the photochemical synthetic system of L-BEP was again chosen to evaluate mixing performance and photochemical reaction efficiency after introduction of nitrogen microbubbles to enhance photon absorption in mini-/microchannels [25]. Another interesting industrial example involving photochemical microfluidic synthesis of vitamin D3 was developed using photoluminiscent substrates based on $\mathrm{LaB}_{3} \mathrm{O}_{6}: \mathrm{Bi}$, Gd whose UVB emission intensity was increased by approximately 11 times when compared with the ultraviolet B (UVB) emission light of a low-power light source (e.g. an $8 \mathrm{~W}$ lamp) [26].

However, the direct irradiation with UV light $(254 \mathrm{~nm})$ of 3-aylestrone and 3-acyl-17-norestrone in micro heterogeneous media (micellar solutions) was not previously reported yet in the literature and we were encouraged to undertake a 
more extensive work. Thus, we carried out an accurate study of the effect of the confined environment of the micelles on the photoreaction mechanism and the selectivity on the product distribution for which we chose the estrone derivatives as the substrates (see Scheme 1). In the same scheme the structures of the surfactants used in this study are also depicted along with the critical micellar concentration $(\mathrm{cmc})$ data for each one.

Controlling the product selectivity of a photoreaction is a great challenge in synthetic organic photochemistry, especially when radical-ion pairs or radical pairs are formed as primary intermediates [27-30]. Zeolites [31, 32], micelles [33, 34], polyolefin films [35], cavitands [36, 37], or dendrimers [38] are water soluble confined assemblies that impart a restricted mobility on the reactive intermediates generated after excitation leading to a noticeable selectivity of the product distribution of the photoreaction. In particular, cationic, anionic and neutral surfactant micelles are confined assemblies that show interesting features. Thus, micelles are capable of solubilizing in water hydrophobic molecules, i.e. organic molecules. Furthermore, the micelles has the ability to: (1) concentrate guest molecules into relatively small effective volumes [33, 39], (2) exist in a dynamic equilibrium and (3) are capable to organize organic substrates [39-41]. Therefore, the confined environment provided by the hydrophobic core of the micelle can be considered as a micro reactor where (photo)reactions can take place, the reactivity of radical species generated can be controlled and, at the same time, can be helpful to direct the selectivity of the (photo)products. Some interesting examples of photoreaction carried out in micellar media as optimal micro reactor that can control the selectivity and yield of the photoproducts can be found in the literature [42-45] and our research group has also contributed with several examples [46-49].

Among the vast number of photochemical transformations, the photo-Fries rearrangement reaction represents a prototypical example to probe the micellar hydrophobic environment, the nature of the counterion and the selectivity on the photoproducts distribution. This photochemical reaction was discovered by Anderson and Reese [50]. Nowadays it is accepted that the photochemical reaction undergoes an in-cage radical mechanism because involves a homolytic cleavage of a carbon-heteroatom bond, i.e. $\mathrm{C}-\mathrm{O}, \mathrm{C}-\mathrm{S}$ and $\mathrm{C}-\mathrm{N}$ and it is well-established that the photoreaction proceeds mainly through the singlet state $[51,52]$.

Herein, we describe the results obtained on the direct irradiation of 3-acetylestrone (1), 3-benzoylestrone (2) and 3-acetyl-17-norestrone (3) in confined and sustainable micellar solutions. From a preparative viewpoint, the photoreaction shows a significant selectivity towards the formation of the [1;3]-acyl migrated 3-hydroxyestrone derivatives in good yields whereas no estrone is formed. The location of the 3-acylsteroids within surfactant micelles (ionic and non-ionic micelles) behaving as micro reactors was demonstrated using NOESY NMR spectroscopy while the binding constant $K_{\mathrm{b}}$ of the substrates was measured by UV-visible spectroscopy.
Scheme 1 Structures of 3-acetylestrone (1), 3-benzoylestrone (2) and 3-acetylnorestrone (3) and surfactants CTAC, SDS and Brij-P35

(a) Structures of 3-acylestrone derivatives.

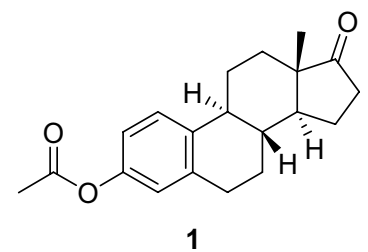

1<smiles>CC12CCC3c4ccc(OC(=O)c5ccccc5)cc4CCC3C1CCC2=O</smiles>

2

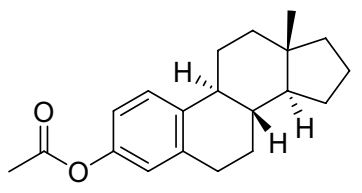

3

(b) Structures of surfactants.

Cationic Surfactant.<smiles>CCCCCCCCCCCCCCCCC[N+](C)(C)Cl</smiles>

Anionic Surfactant.<smiles>CCCCCCCCCCCCOS(=O)(=O)[O-]</smiles>

Non-ionic Surfactant.

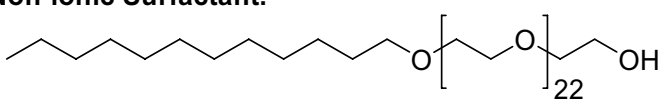

Cetyl trimethyl ammonium chloride (CTAC) cmc: $1.25 \mathrm{mM}$

Sodium dodecyl sulfate (SDS) cmc: $8.2 \mathrm{mM}$

Polyoxyethylene(22)lauryl ether (Brij P35) 


\section{Results}

\subsection{Photoirradiation of 3-acylestrone derivatives in cyclohexane and in micellar media}

In order to analyze if cationic, anionic and neutral micelles can function as photochemical micro reactors and are able to induce photoproduct selectivity from 3-acylestrone derivatives 1-3 (for structures, refer to Scheme 1), the photo-Fries rearrangement reaction of these steroids was systematically investigated in ionic and non-ionic micellar media and was compared with those results obtained in homogeneous media such as cyclohexane. The general photochemical reaction of 3-acyl estrone derivatives 1-3 is depicted in Scheme 2.

Irradiation of estrones $\mathbf{1}$ and $\mathbf{2}$ were carried out in cyclohexane and in micellar solutions of SDS, CTAC and Brij-P35, respectively, with $\lambda_{\text {exc }}=254 \mathrm{~nm}$ under $\mathrm{N}_{2}$ atmosphere providing the photoproducts expected from the photoFries rearrangement, viz. formation of the ortho regioisomers (1a and $\mathbf{1 b}$ from 3-acetylestrone (1) and 2a and $\mathbf{2 b}$ from 3-benzoylestrone (2)) and estrone (4). Furthermore, compounds 5 and lumiestrone $\mathbf{6}$ were also detected in the photolysed reaction mixtures and were formed through a photochemical epimerization reaction of compounds 1a and 4, respectively (see Scheme 2). The chemical yields of the photoproducts are collected in Table 1 and is apparent from the data that the [1;3]-migrated photoproducts, viz. compounds 1a, $\mathbf{1 b}$ and $\mathbf{5}$ from ester $\mathbf{1}$ and $\mathbf{2 a}$ and $\mathbf{2 b}$ from ester $\mathbf{2}$, are the main photoproducts when esters $\mathbf{1}$ and $\mathbf{2}$ are consumed in up to $40-50 \%$ yield.

Another hint the data collected in Table 1 brings about is the high selectivity in favor of the formation of the [1;3]-migrated photoproducts (compounds $\mathbf{1 a}, \mathbf{1 b}, \mathbf{5}, \mathbf{2 a}$ and $\mathbf{2 b}$ ) when the photoreaction was performed in micellar solutions. Indeed, the yields of these photoproducts increase noticeably whereas the formation of estrone $\mathbf{4}$ is almost inhibited. However, this selectivity is not observed in homogeneous media such as cyclohexane where estrone $\mathbf{4}$ is formed in $35 \%$ yield when ester $\mathbf{1}$ was irradiated while both photoproducts estrone $\mathbf{4}$ and lumiestrone $\mathbf{6}$ are formed in $15 \%$ from ester 2.

The migration of the acyl group occurred with a noticeable selectivity upon irradiation of esters $\mathbf{1}$ and $\mathbf{2}$ in micellar solutions. In fact, the shifting of the acyl group to position 2 of the aryl moiety is preferred over the migration of the same group to position 4 and depends on the nature of the surfactant used. For example, in the case of ester 1 the ratio $(\mathbf{1 a}+\mathbf{5}) / \mathbf{1 b}$ changes from 6.2 in SDS to 1.8 in Brij-P35 to 1.3 in CTAC showing that cationic surfactants like CTAC diminishes the selectivity of the acetyl migration to positions 2 and 4, respectively, while with the other kind of surfactants favors the migration of the acetyl group to position 2 over position 4 . Similarly, in the case of ester $\mathbf{2}$ the $\mathbf{2 a} / \mathbf{2} \mathbf{b}$ ratio moves from 6.4 to 1.4 and again surfactant CTAC provides
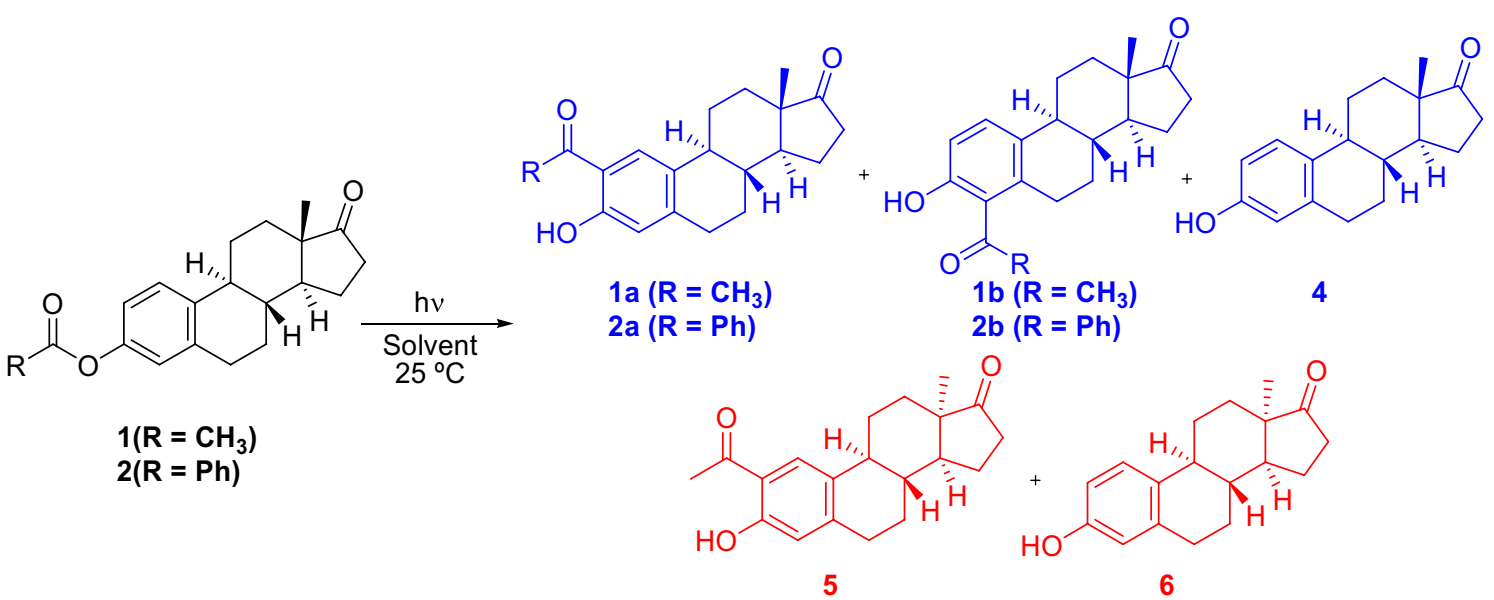

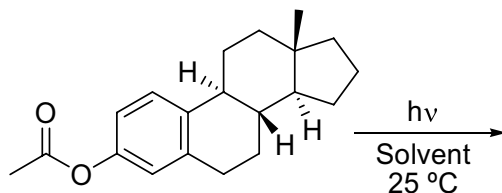

3

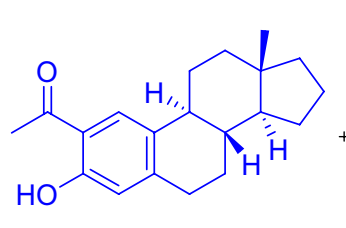

$3 a$

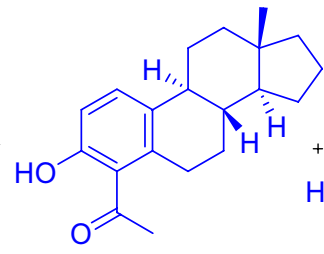

$3 b$<smiles>C[C@]12CCC[C@H]1[C@@H]1CCc3cc(O)ccc3[C@@H]1CC2</smiles>

7

Scheme 2 The photo-Fries rearrangement of 3-acylestrones (1 and 2) and 3-acetyl-17-norestrone (3) 
Table 1 Yields of photoproducts and reaction quantum yield $\left(\phi_{\mathrm{R}}\right)$ measured in cyclohexane and in micellar media for 3-acylestrones 1 and 2

\begin{tabular}{|c|c|c|c|c|c|c|c|}
\hline \multirow[t]{2}{*}{ Substrate } & \multirow[t]{2}{*}{ Solvent } & \multirow[t]{2}{*}{ Surfactant } & \multicolumn{4}{|c|}{ Yields (\%) } & \multirow[t]{2}{*}{$\phi_{R}$} \\
\hline & & & $1 \mathrm{a}$ & $1 b$ & 4 & 5 & \\
\hline \multirow[t]{4}{*}{1} & Cyclohexane & - & 34 & 14 & 35 & 5 & 0.05 \\
\hline & $\mathrm{H}_{2} \mathrm{O}$ & SDS (0.1 M) & 59 & 13 & 0 & 21 & 0.03 \\
\hline & $\mathrm{H}_{2} \mathrm{O}$ & Brij-P35 (0.01 M) & 59 & 33 & $<1$ & 0 & 0.06 \\
\hline & $\mathrm{H}_{2} \mathrm{O}$ & CTAC $(0.02 \mathrm{M})$ & 40 & 41 & $<1$ & 13 & 0.01 \\
\hline \multirow[t]{2}{*}{ Substrate } & Solvent & Surfactant & & & & & $\phi_{R}$ \\
\hline & & & $2 \mathrm{a}$ & $2 b$ & 4 & 6 & \\
\hline \multirow[t]{4}{*}{2} & Cyclohexane & - & 58 & 22 & 11 & 4 & 0.01 \\
\hline & $\mathrm{H}_{2} \mathrm{O}$ & $\operatorname{SDS}(0.1 \mathrm{M})$ & 60 & 25 & 1 & 0 & 0.01 \\
\hline & $\mathrm{H}_{2} \mathrm{O}$ & Brij-P35 (0.01 M) & 70 & 11 & 4 & 1 & 0.01 \\
\hline & $\mathrm{H}_{2} \mathrm{O}$ & CTAC (0.02 M) & 57 & 42 & $<1$ & 0 & 0.01 \\
\hline
\end{tabular}

Yield of photoproducts determined by ${ }^{1} \mathrm{H}$ NMR spectroscopy in the reaction mixture. Concentration of 3-acylestrones: $5.0 \times 10^{-3} \mathrm{M}$

Actinometer: $\mathrm{KI}(0.6 \mathrm{M}), \mathrm{KIO}_{3}(0.1 \mathrm{M})$ and $\mathrm{Na}_{2} \mathrm{~B}_{2} \mathrm{O}_{7} \cdot 10 \mathrm{H}_{2} \mathrm{O}(0.01 \mathrm{M})$ solution in water; $\phi\left(\mathrm{I}_{3}-\right)=0.74 ; \lambda_{\text {exc }}=254 \mathrm{~nm}$. (37) error: \pm 0.01

the lower ratio suggesting that the migration of benzoyl group occurs without significant selectivity.

The quantum yields of consumption $\left(\phi_{\mathrm{R}}\right)$ of esters 1 and 2 in cyclohexane and micellar media were also measured (see Table 1). The $\phi_{\mathrm{R}}$ values of ester 1 depend on the reaction solvent. Similar values were obtained in cyclohexane and in micellar Brij-P35 solution whereas lower $\phi_{\mathrm{R}}$ values were found in SDS and CTAC micellar solutions. In the case of ester 2 no solvent dependence was observed and the $\phi_{R}$ values were 0.01 . However, the $\phi_{\mathrm{R}}$ values for both esters 1 and 2 varied from 0.06 to 0.01 implying that the photoreaction occurred smoothly and could compete with radiative and non-radiative pathways.

UV-visible spectroscopy was employed to follow the photochemical reaction in cyclohexane and in micellar solution. Figure 1a depicts the time-resolved UV-visible absorption spectra of the photoreaction of 3-acetyl estrone (1) in SDS $(0.10 \mathrm{M})$ micellar solution while Fig. 1b shows the variation of the UV-visible absorption spectra with reaction time for ester 2 in CTAC $(0.02 \mathrm{M})$ micellar solution. New absorption bands located at $325 \mathrm{~nm}$ and at $348 \mathrm{~nm}$ for esters $\mathbf{1}$ and $\mathbf{2}$, respectively, rise with irradiation time in both micellar solutions. These bands were assigned to the $n, \pi^{*}$ transition of the carbonyl group of the ortho-rearranged photoproducts $[53,54]$ and similar spectral behavior was also observed in cyclohexane, CTAC and Brij-P25 for ester 1 and in cyclohexane, SDS and Brij-P35 for ester 2 (see Figures S1 and S2 in Supporting Information). The energy of the $n, \pi^{*}$ transition band $(E(\lambda))$ was correlated with the $\mathrm{E}_{\mathrm{T}}(30)$ Reichardt's polarity parameter [55-57] and it was found that the energy values $(E(\lambda))$ were not affected by the solvent polarity when moving from cyclohexane to the micellar solutions (see Figure S4 in Supporting Information).
The relative absorbance profiles ( $A_{\text {rel }}$ vs. t) of the ortho regioisomers formation (1a, $\mathbf{1 b}$ and $\mathbf{5}$ from ester $\mathbf{1}$ and $\mathbf{2 a}$ and $\mathbf{2 b}$ from ester $\mathbf{2}$ ) were measured in cyclohexane and in micellar solutions and these grow-in plots are shown in Fig. 1c, d, respectively. In the case of ester 1 , the relative rate of formation of photoproducts $\mathbf{1 a}, \mathbf{1 b}$ and $\mathbf{5}$ measured in cyclohexane is higher than in micellar solution. Comparing the relative rates between the micelle solutions, it was found that the relative rate in SDS solution is higher than CTAC and Brij-P35 solutions while these last two micellar systems were similar. The finding leads to the conclusion that in micellar systems radiative and non-radiative decay rates compete in a similar extent with the photoreaction pathway. However, in the case of ester $\mathbf{2}$ it was found that the relative rate of formation of photoproducts $\mathbf{2 a}$ and $\mathbf{2} \mathbf{b}$ are similar in cyclohexane just like in micellar solutions.

It is worth to mention that during the irradiation of esters 1 photoproduct 5 was formed and the chemical yield depends on the solvent used (see Table 1). The formation of this photoproduct is due to the Norrish Type I photoreaction that competes with the photo-Fries rearrangement reaction. Thus, epimerization of the methyl group at C-13 of photoproduct 1a was observed in cyclohexane, SDS and CTAC micellar solutions providing compound $\mathbf{5}$ with yields between 5 and $21 \%$. The epimerization of the methyl group in photoproduct 1a occurs because this photoproduct is a chromophore that can absorb light of $254 \mathrm{~nm}$. Then, the Norrish Type I photoreaction proceeds smoothly promoting the homolytic fragmentation of the $\mathrm{C} \alpha-\mathrm{C}=\mathrm{O}$ bond efficiently involving the formation of a biradical intermediate which is responsible of the epimerization of $\mathrm{C} \alpha$ as can be seen in Scheme 3 for the case of ortho-regioisomer 1a. Likewise, during irradiation of ester $\mathbf{2}$ in cyclohexane, estrone $\mathbf{4}$ was photo converted into lumiestrone $\mathbf{6}$ in very low yield (see Table 1) allowing the 

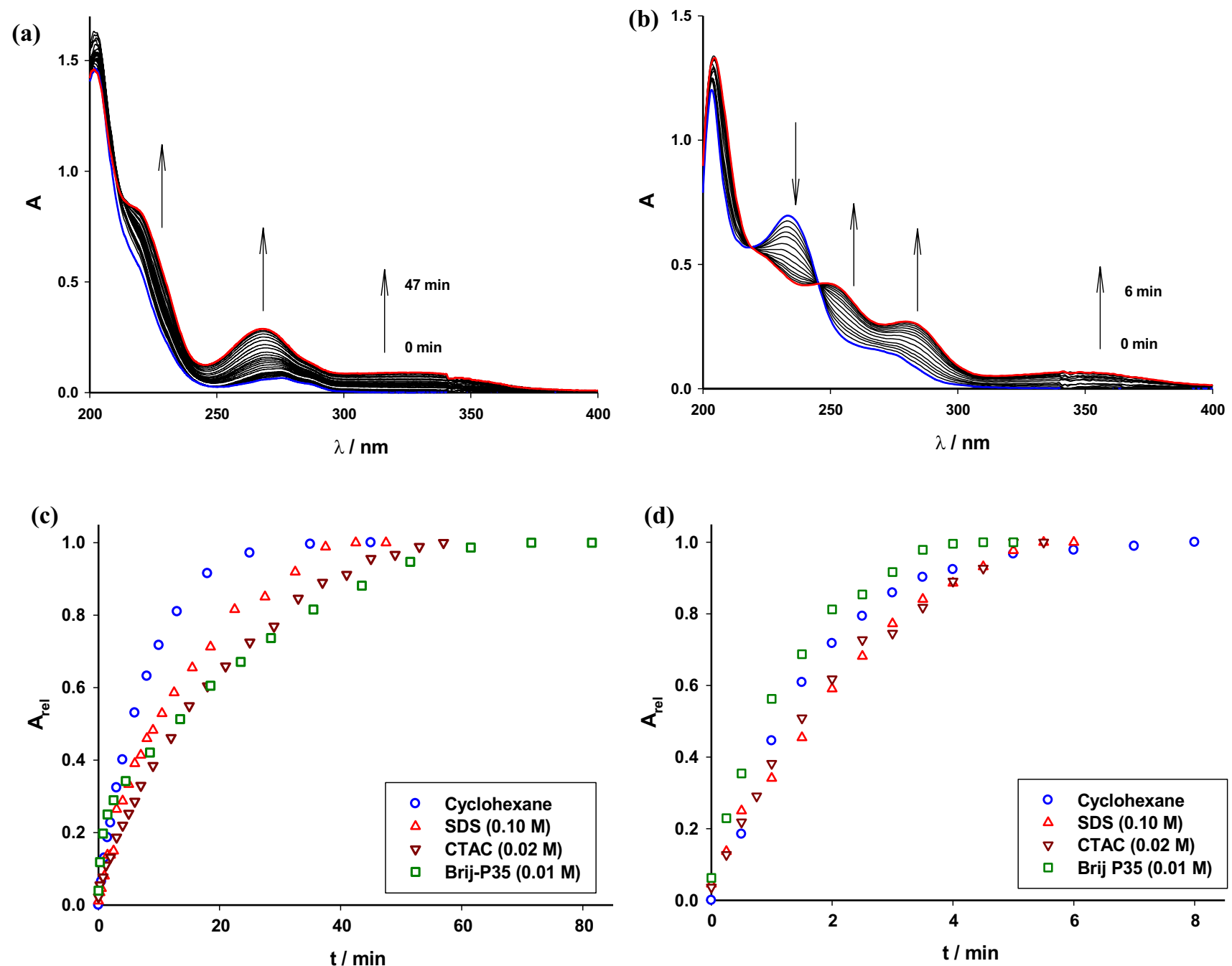

Fig. 1 Time-resolved UV-visible spectra of: a 3-acetylestrone (1) in micellar solution of SDS $(0.10 \mathrm{M})$ and $\mathbf{b}$ 3-benzoylestrone (2) in micellar solution of CTAC $(0.02 \mathrm{M})$. Relative absorbance profiles of:

c 3-acetylestrone (1) and b 3-benzoylestrone (2) in cyclohexane and different micellar solutions

Scheme 3 The Norrish Type I photoreaction of orthoregioisomer (1a) and biradical intermediate

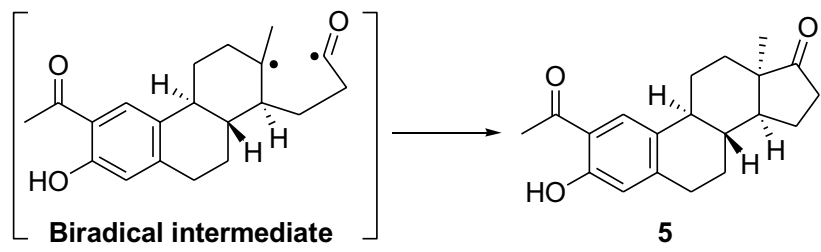

The strong photostability observed for compounds $\mathbf{1 b}$, $\mathbf{2 a}$ and $\mathbf{2 b}$ was ascribed to the formation of $E$-keto tautomer in the ground state as it was previously described in the literature [22], The formation of this tautomer is due to the excited state intramolecular proton transfer process (ESIPT) [13, 61-64] of the ortho-regioisomer to produce the Z-keto tautomer $\mathbf{A}$ in the excited state as it is depicted in Scheme 4 for the case of compound $\mathbf{2 a}$. Deactivation with twisting 
Scheme 4 Z-E keto tautomerism of compound $\mathbf{2 a}$ and photoinduced epimerization reaction of 1a
Table 2 Yields of photoproducts $^{\mathrm{a}}$ and reaction quantum yield $\left(\phi_{\mathrm{R}}\right)$ measured in cyclohexane and in micellar media for 3-acetyl-17norestrone 3

(a)Cis-trans keto tautomerism of compound 2a.

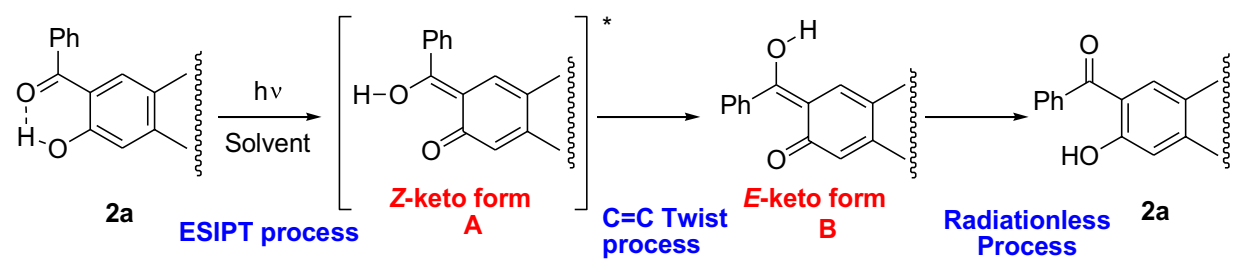

(b) Non-planarity of compound 1a and epimerization reaction.
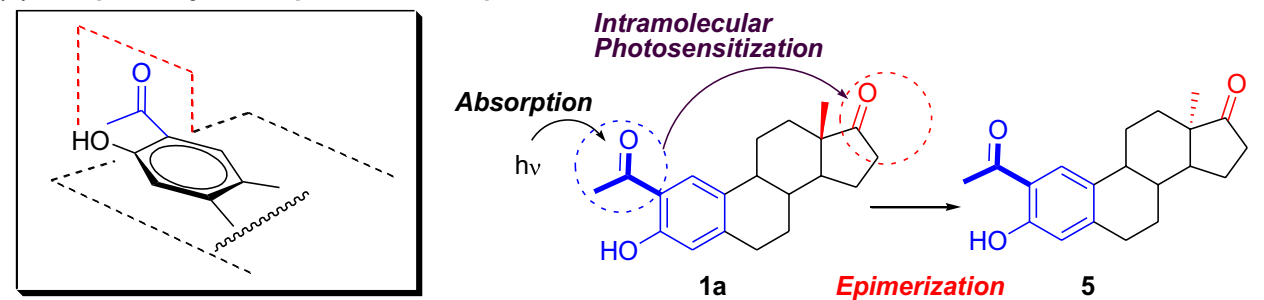

\begin{tabular}{|c|c|c|c|c|c|c|}
\hline \multirow[t]{2}{*}{ Substrate } & \multirow[t]{2}{*}{ Solvent } & \multirow[t]{2}{*}{ Surfactant } & \multicolumn{3}{|c|}{ Yields (\%) } & \multirow[t]{2}{*}{$\phi_{R}$} \\
\hline & & & $3 a$ & $3 b$ & 7 & \\
\hline \multirow[t]{4}{*}{3} & Cyclohexane & - & 32 & 33 & 22 & 0.03 \\
\hline & $\mathrm{H}_{2} \mathrm{O}$ & $\operatorname{SDS}(0.1 \mathrm{M})$ & 22 & 23 & 0 & 0.02 \\
\hline & $\mathrm{H}_{2} \mathrm{O}$ & Brij-P35 (0.01 M) & 20 & 31 & 8 & 0.01 \\
\hline & $\mathrm{H}_{2} \mathrm{O}$ & CTAC $(0.02 \mathrm{M})$ & 15 & 26 & 0 & 0.01 \\
\hline
\end{tabular}

Yield of photoproducts determined by ${ }^{1} \mathrm{H}$ NMR spectroscopy in the reaction mixture. Concentration of 3-acylestrones: $5.0 \times 10^{-3} \mathrm{M}$

Actinometer: $\mathrm{KI}(0.6 \mathrm{M}), \mathrm{KIO}_{3}(0.1 \mathrm{M})$ and $\mathrm{Na}_{2} \mathrm{~B}_{2} \mathrm{O}_{7} \cdot 10 \mathrm{H}_{2} \mathrm{O}(0.01 \mathrm{M})$ solution in water; $\phi\left(\mathrm{I}_{3}{ }^{-}\right)=0.74$; $\lambda_{\text {exc }}=254 \mathrm{~nm}$. (37) error: \pm 0.01

of the newly produced $\mathrm{C}=\mathrm{C}$ bond of the tautomer before intersystem crossing to the triplet excited state occurs and then, the Z-keto tautomer A converts into $E$-keto tautomer $\mathbf{B}$ in its ground state involving a radiationless process. This photophysical behavior is usually observed with $\beta$-hydroxy carbonyl compounds such as 2'-hydroxychalcones in $\pi-\pi^{*}$ excited states, where the carbonyl group becomes more basic and the phenolic group usually becomes more acidic favoring the one-way $Z-E$ isomerization of 2'-hydroxychalcones [65-68]. Therefore, the photostability of regioisomers $\mathbf{1 b}$, $\mathbf{2 a}$ and $\mathbf{2 b}$ can be explained taking into account the presence of the $\beta$-hydroxy carbonyl moiety in their structures that promotes the ESIPT process efficiently after absorption of light and causing the deactivation of the Z-keto tautomer through radiative and non-radiative pathways. Consequently, the Norrish Type I photoreaction does not compete with the tautomeric and deactivation pathways and the epimerization of these photoproducts was not observed during the irradiation of esters $\mathbf{1}$ and $\mathbf{2}$. Noteworthy, the photostability of compounds $\mathbf{1 b}, \mathbf{2 a}$ and $\mathbf{2 b}$ was also observed in micellar solution implying that the ESIPT process proceeds efficiently within the hydrophobic core of the micelle independent of the nature of the surfactant used. The distinct photochemical behavior that compound 1a showed in comparison with regioisomers $\mathbf{1 b}, \mathbf{2 a}$ and $\mathbf{2} \mathbf{b}$ can be attributed to the non-planarity of the acetyl group with the benzene moiety partially preventing the intramolecular hydrogen bonding between the hydroxyl group and the carbonyl group (see Scheme 4). Thus, the ESIPT process is not favored and does not compete with the epimerization reaction of the carbonyl group at $\mathbf{C}-17$ in compound $\mathbf{1 a}$ providing smoothly compound $\mathbf{5}$. The driving force of the epimerization is due to an intramolecular triplet photosensitization from the aryl moiety to the carbonyl group at C-17 of compound 1a, in agreement with was previously reported in the literature for the case of $3 \alpha-\mathrm{d}$ imethylphenylsilyloxyandrostanone derivatives $[18,69]$.

The photochemistry of 3-acetyl-17-norestrone in confined media was also studied as an example of an steroid without the presence of the carbonyl group at $\mathrm{C}-17$ which was demonstrated to be responsible of the competitive Norrish type I reaction. Thus, direct irradiation $\left(\lambda_{\text {exc }}=254 \mathrm{~nm}\right)$ of 3-acetyl17-norestrone (3) in micellar solution and cyclohexane under $\mathrm{N}_{2}$ atmosphere was carried out and it was found to provide the expected photoproducts from the photo-Fries rearrangement, viz. formation of the ortho-regioisomers (3a and $\mathbf{3 b}$ ) and 17-norestrone (7) (see Scheme 1). No epimerization of 
the photoproducts was observed because compound $\mathbf{3}$ does not bear a carbonyl group at $\mathrm{C}-17$. The chemical yields are shown in Table 2 and were determined using NMR spectroscopy. As is apparent from the data collected in Table 2, the ortho-regioisomers $\mathbf{3 a}$ and $\mathbf{3 b}$ were the main photoproducts formed in micellar solution when ester $\mathbf{3}$ was consumed in up to $50 \%$ yield. Furthermore, a noticeable selectivity of the photoreaction was observed and the confined media working as a micro-reactor vessel inhibited the formation of 17-norestrone implying that the diffusion of the radical species generated within the hydrophobic core of the micelle did not occur. This interesting behavior was not observed in homogeneous media such as cyclohexane because 17-norestrone is formed in $22 \%$ yield due to a free diffusion of the radical species into the bulk. Additionally, the selectivity of the acetyl migration depended on the nature of the surfactant used. In fact, the $\mathbf{3 b} / \mathbf{3 a}$ ratio was found to increase from 1.05 in SDS to 1.55 in Brij-P35 till 1.73 in CTAC where the [1;3]-acetyl migration is favored to position 4 .

The quantum yields of consumption $\left(\phi_{\mathrm{R}}\right)$ of ester $\mathbf{3}$ in cyclohexane and micellar media were measured displaying a slight dependence with the reaction solvent (see Table 2). The $\phi_{R}$ values move from 0.03 in cyclohexane to 0.01 in CTAC and Brij-P35 micellar solution suggesting that the photo-Fries rearrangement reaction proceeds smoothly competing with radiative and non-radiative pathways.

The photoreaction of ester 3 in Brij-P35 0.01 M micellar solution was also followed by UV-visible spectroscopy and a new band located at $330 \mathrm{~nm}$ rises with irradiation time (see Fig. 2a) which was assigned to the $n, \pi^{*}$ transition of the carbonyl group of the ortho-rearranged photoproducts $[53,54]$. Similar results were obtained in cyclohexane and in micellar solutions of SDS and CTAC (see Figure S3 in Supporting Information). Additionally, it was found that the energy of the new band was not affected by the variation of the solvent polarity reflecting a similar behavior as it was obtained when esters $\mathbf{1}$ and $\mathbf{2}$ were analyzed.

The relative absorbance profiles ( $A_{\text {rel }}$ vs. $t$ ) of photoproducts $\mathbf{3 a}$ and $\mathbf{3 b}$ were measured in all the solvents studied and the grow-in profiles are depicted in Fig. 2b. Notice that the formation profiles measured in cyclohexane and SDS micellar solution grew-in with the same window of irradiation time (10 $\mathrm{min})$. However, the formation profiles of ortho-regioisomers $\mathbf{3 a}$ and $\mathbf{3 b}$ measured in CTAC and Brij-P35 micellar solutions were similar and required $c a$. $50 \mathrm{~min}$ of irradiation time. These findings lead to the conclusion that the nature of the surfactant noticeably affects the rate of formation of the photoproducts. In fact, anionic surfactant such as SDS accelerates the formation of $\mathbf{3 a}$ and $\mathbf{3 b}$ as cyclohexane does whereas cationic CTAC and neutral Brij-P35 surfactants diminish significantly the formation of the ortho-regioisomers suggesting the radiative and non-radiative decay rates compete in a high extent with the photoreaction pathway.

\subsection{Binding constants $\left(K_{b}\right)$ of 3-acylestrone (1 and 2) and 3-acetyl-17-norestrone (3) in micellar media}

Micellar solutions, which are often considered as micro photochemical reactors, are micro heterogeneous systems where photoreactions can be performed. In this regard, UV-visible spectroscopy studies of 3-acylestrone derivatives (1-3) in micellar solution were conducted in order to determine the binding constant $\left(K_{\mathrm{b}}\right)$ between the surfactants (SDS, CTAC and Brij-P35) and the steroids 1-3. The methodology employed in this study has been previously reported for the determination of binding constants of aryl acetamide and
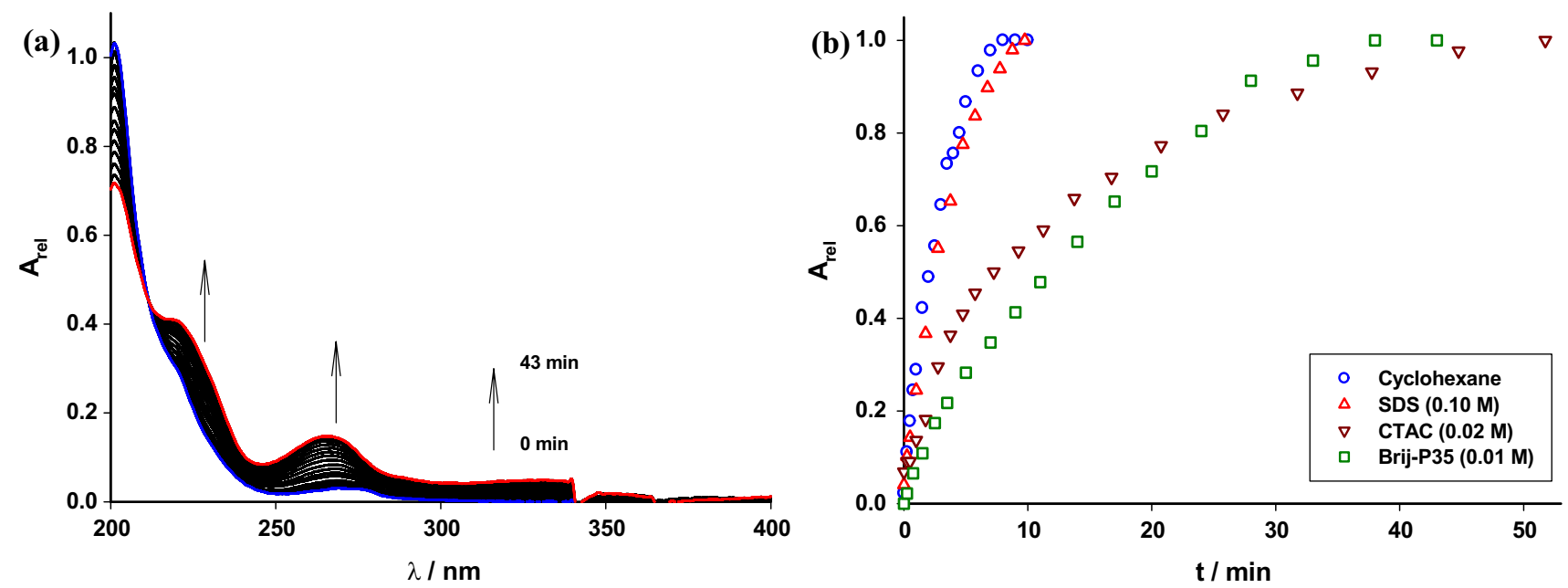

Fig. 2 a Time-resolved UV-visible spectra of 3-acetyl-17-norestrone (3) in micellar solution of Brij-P35 (0.01 M). b Relative absorbance $\left(A_{\text {rel }}\right)$ profiles of 3-acetylnorestrone (3) in cyclohexane and different micellar solutions 


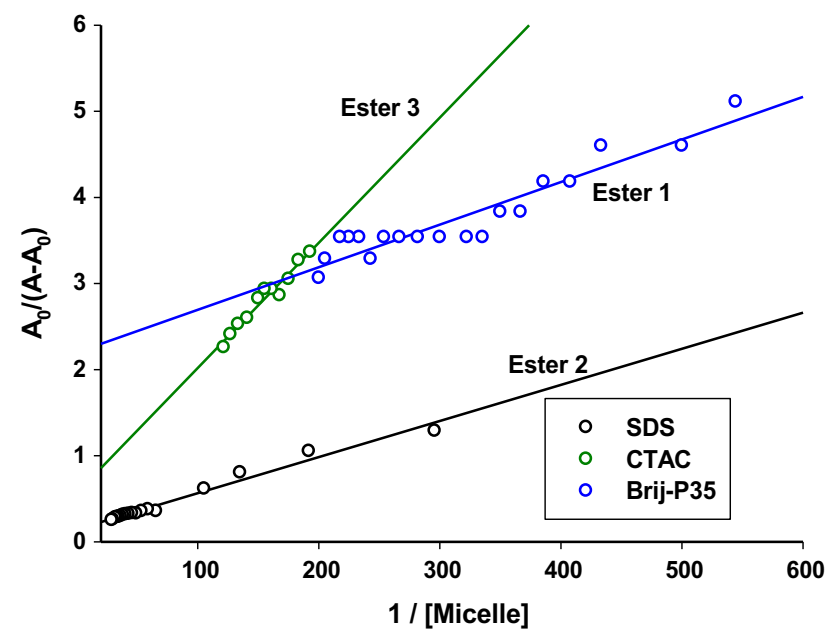

Fig. 3 Plot of the $A_{0} /\left(A-A_{0}\right)$ values of 3-acylestrone derivatives (13) $v s$ the reciprocal concentration of the micelle: (black unfilled circle) SDS; (blue unfilled circle) Brij-P35; (green unfilled circle) CTAC

aryl benzoates [46, 47]. The analysis of bathochromic and hyperchromic shifts of the lower energy absorption band of the steroids $\mathbf{1}-\mathbf{3}$ in water by addition of increasing amounts of surfactant led to evaluate the extent of binding of steroids to the surfactants within the hydrophobic core of the micelle (batho- and hyperchromic shifts, see Figures S5-S7 in Supporting Information). Indeed, the binding process can be described according to Eq. 1 where $K_{\mathrm{b}}$ is the binding constant, $\mathrm{S}$ represents the steroids, Surf the surfactants and [S-Surf] the complex formed between steroids and the surfactant.

$[\mathrm{S}]+[$ Surf $] \stackrel{K_{b}}{\rightleftarrows}[\mathrm{S}-$ Surf $] \quad K_{b}=\frac{[\mathrm{S}-\text { Surf }]}{[\mathrm{S}][\text { Surf }]}$.

Application of Lambert-Beer law on Eq. 1 provided Eq. 2 where $A_{0}$ and $A$ are the absorbances at the maximum wavelength in the absence and presence of surfactant, respectively, $\varepsilon_{\mathrm{C}}$ is the molar absorptivity of the complex whereas $\varepsilon_{\mathrm{S}}$ is the steroids molar absorptivity. Mathematical rearrangement of Eq. 2 provided Eq. 3 where a linear relationship is observed between $\left[A_{0} /\left(A-A_{0}\right)\right]$ and the reciprocal of the concentration of the surfactant.

$$
\begin{aligned}
& \frac{\left(A-A_{0}\right)}{A_{0}}=\frac{\varepsilon_{C} \cdot K_{b} \cdot[\text { Surf }]}{\varepsilon_{S} \cdot\left(1+K_{b} \cdot[\text { Surf }]\right)}, \\
& \frac{A_{0}}{\left(A-A_{0}\right)}=\frac{\varepsilon_{S}}{\varepsilon_{C}}+\frac{\varepsilon_{S}}{\varepsilon_{C} \cdot K_{b}} \frac{1}{[\text { Surf }]},
\end{aligned}
$$

Nice linear correlations were obtained after plotting the data according to Eq. 3 of ester $\mathbf{1}$ in Brij-P35, ester $\mathbf{2}$ in SDS and ester $\mathbf{3}$ in CTAC micellar solutions, respectively. The linear correlations are depicted in Fig. 3 including the best linear regression curves while the straight lines and the corresponding linear regression curves for the other cases are collected in Figure S8 (see ESI).

The $K_{\mathrm{b}}$ values for the 3-acylestrone derivatives 1-3 were calculated from the ratio of the intercept and the slope of the regression curve and the data thus obtained are collected in Table 3 . The $K_{\mathrm{b}}$ values obtained for the 3-acylestrone derivatives (1-3) are typical of the family of steroids such as estrone, $17 \alpha$-ethynylestradiol, $17 \beta$-estradiol, testosterone, progesterone and estriol and estimation of $K_{\mathrm{b}}$ values $\leq 600 \mathrm{M}^{-1}$ in SDS, CTAC and Brij-P35 micellar solutions have been reported [70-72]. Some $K_{\mathrm{b}}$ values of the steroids were measured in anionic, cationic and neutral surfactants using the data that have been previously determined by fluorescence emission spectroscopy [70] and the double reciprocal plots thus obtained as well as some representative binding constants $\left(K_{\mathrm{b}}\right)$ are shown in Figure $\mathrm{S} 9$ and Table $\mathrm{S} 1$ (see ESI).

\subsection{Use of 1D and 2D NMR spectroscopy in the estimation of the location of 3acylestrone (1 and 2) and 3-acetyl-17-norestrone (3) in micellar media}

Once the binding constants of steroids 1-3 have been measured, we looked for the qualitative location of steroids within the hydrophobic core of the micelles and ${ }^{1} \mathrm{H}$ NMR and 2D NMR (NOESY experiments) studies of guest molecules within surfactant micelles to gain an understanding of the reactants' positioning were conducted. Furthermore, this kind of analyses using NMR spectroscopy to assess the location of a solute within the micellar confined media has been previously described [73-77]. To begin with the NMR spectroscopy analyses, the ${ }^{1} \mathrm{H}$ NMR of surfactants CTAB, SDS and Brij-P35 in $\mathrm{D}_{2} \mathrm{O}$ were recorded in the presence and absence of steroids $\mathbf{1}-\mathbf{3}$ showing differential effects on the various protons of the surfactants, causing slightly upfield and downfield shifts ( $\sim 0.1-0.01 \mathrm{ppm})$ and these magnitudes are much above the value for typical errors in the chemical shifts ( $\sim 0.002$ ppm) [75]. As an example, Fig. 4 shows the comparison of the ${ }^{1} \mathrm{H}$ NMR spectra of surfactant CTAC in the absence and the presence of 3-acetylestrone (1)

Table 3 Constants of binding $\left(K_{b}\right)$ of the 3 -acylestrone derivatives measured in different micro heterogeneous media

\begin{tabular}{llll}
\hline & \multicolumn{3}{l}{$K_{b}\left(\mathrm{M}^{-1}\right)$} \\
\cline { 2 - 4 } Surfactant & 1 & 2 & 3 \\
\hline SDS $(0.10 \mathrm{M})$ & 18 & 35 & 23 \\
CTAC $(0.02 \mathrm{M})$ & 147 & 117 & 80 \\
Brij-P35 $(0.01 \mathrm{M})$ & 428 & 51 & 96 \\
\hline
\end{tabular}




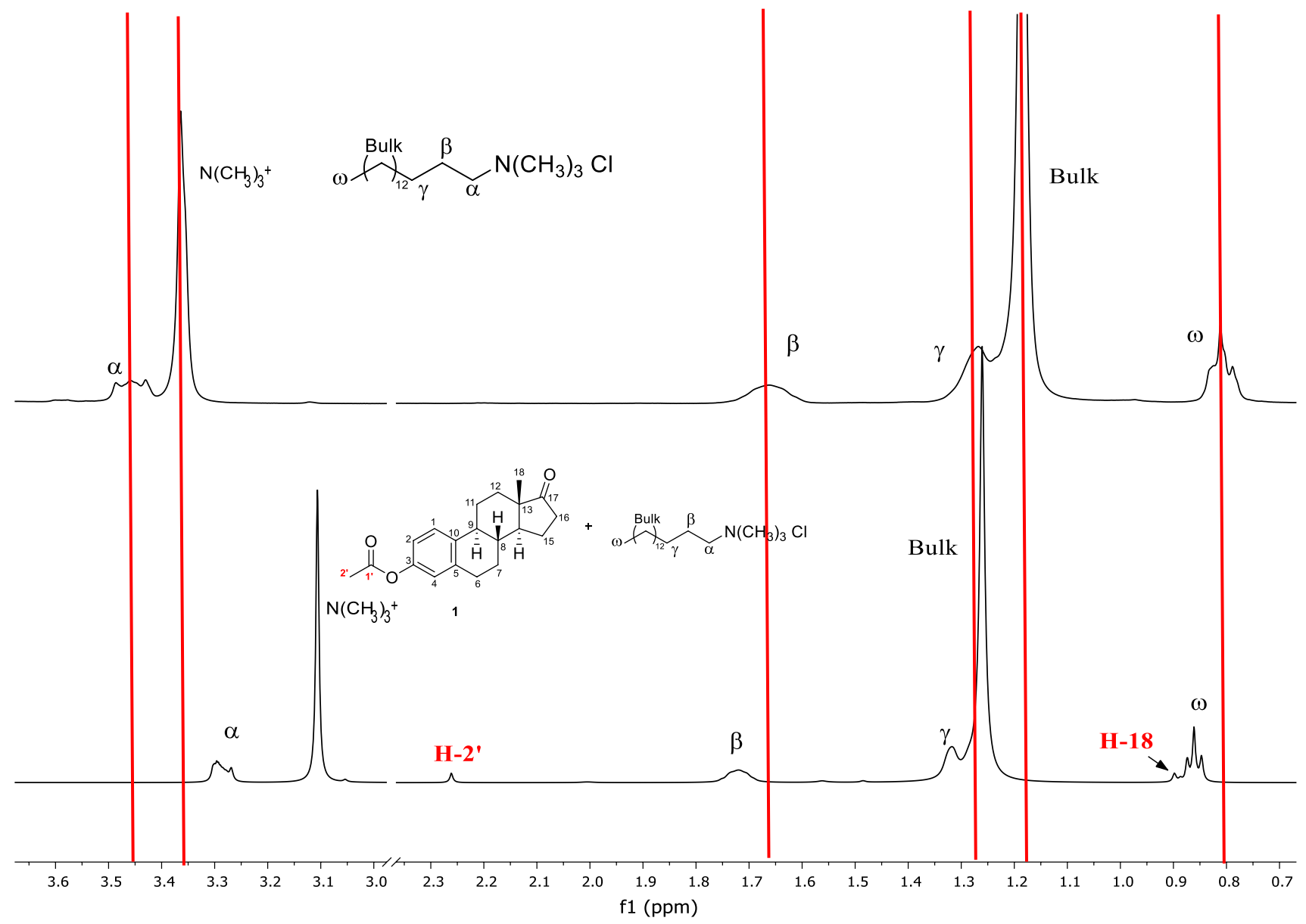

Fig. $4{ }^{1} \mathrm{H}$ NMR spectra of surfactant CTAC recorded in $\mathrm{D}_{2} \mathrm{O}$ in: a the absence and $\mathbf{b}$ the presence of 3-acetylestrone (1)

where a change in the chemical shift of the surfactant was clearly observed. Similar spectroscopic behaviors were also observed for some surfactants in the presence of the guest molecules such as esters $\mathbf{2}$ and $\mathbf{3}$, respectively, and the results are shown in Figures S10-S13 (see ESI).

The differential chemical shifts $(\Delta \delta)$ for surfactants in the presence of esters $\mathbf{1}, \mathbf{2}$ and $\mathbf{3}$ are collected in Table 4. These $\Delta \delta$ values outline the intimate interaction between the esters and the hydrocarbon chains of the surfactants displaying the significant role of the esters have on the surfactant proton shift. Thus, the differential chemical shifts shown in Tables 4 suggest that the esters $\mathbf{1 - 3}$ could be located in the hydrophobic core as well as the shell of the surfactant micelles. This behavior can be ascribed to the high disorder of the hydrocarbon chains within the hydrophobic core of the micelles favoring the intimate interaction of the esters with all the proton nuclei of the hydrocarbon chains of the surfactant and consequently, displaying a differential chemical shifts of each proton nuclei. This methodology has been previously used to analyze the effect of substrates on the chemical shifts of the surfactants $[46,73]$.
Taking into account that a differential chemical shifts $(\Delta \delta)$ was observed in the presence of esters $\mathbf{1}-\mathbf{3}$, the next step was to confirm qualitatively the location of the esters within the hydrophobic core of the micelle employing $2 \mathrm{D}$ NMR spectroscopy. The extent of co-aggregation in water between two different kinds of surfactants or the localization of guest molecules within the micelle have been often determined using NOESY experiments [46-49, 73-77]. In addition, these experiments give satisfactory results when cross-peaks between diagnostic signals of the substrates and the surfactants, respectively, are noticed in the corresponding contour plots [46-49].

Thus, the NOESY experiment performed in $\mathrm{D}_{2} \mathrm{O}$ for a solution of SDS $(50 \mathrm{mM})$ in the presence of 3-acetylestrone (1) $(50 \mathrm{mM})$ at room temperature is shown in Fig. 5 and the labels of the protons of the surfactant SDS and those of compound $\mathbf{1}$ are also depicted in the same figure. The inset black frames recognize the NOE (Nuclear Overhauser Effect) between the signals belonging to the aromatic protons $(\mathrm{H}-1, \mathrm{H}-2$ and $\mathrm{H}-4)$ and to the aliphatic protons $(\mathrm{H}-2$ ' and $\mathrm{H}-18$ ) of 3-acetylestrone and the signals of the surfactant 
Table 4 Differential chemical shifts $(\Delta \delta)$ for surfactants SDS, Brij-P35 and CTAC in the presence of esters 1-3

\begin{tabular}{|c|c|c|c|c|c|c|c|}
\hline & & $\alpha-\mathrm{CH}_{2}$ & $\beta-\mathrm{CH}_{2}$ & Bulk & $\omega-\mathrm{CH}_{3}$ & & \\
\hline SDS & $\delta / \mathrm{ppm}$ & 4.04 & 1.69 & 1.31 & 0.90 & & \\
\hline \multirow[t]{3}{*}{$\mathrm{SDS}+\mathbf{1}$} & $\delta / \mathrm{ppm}$ & 4.02 & 1.66 & 1.26 & 0.87 & & \\
\hline & $\Delta \delta / \mathrm{ppm}$ & 0.02 & 0.03 & 0.05 & 0.03 & & \\
\hline & & $\mathrm{N}\left(\mathrm{CH}_{3}\right)_{3}{ }^{+}$ & $\alpha-\mathrm{CH}_{2}$ & $\beta-\mathrm{CH}_{2}$ & $\gamma-\mathrm{CH}_{2}$ & Bulk & $\omega-\mathrm{CH}_{3}$ \\
\hline CTAC & $\delta / \mathrm{ppm}$ & 3.38 & 3.48 & 1.68 & 1.29 & 1.20 & 0.83 \\
\hline \multirow[t]{3}{*}{$\mathrm{CTAC}+\mathbf{1}$} & $\delta / \mathrm{ppm}$ & 3.11 & 3.29 & 1.73 & 1.33 & 1.26 & 0.86 \\
\hline & $\Delta \delta / \mathrm{ppm}$ & 0.27 & 0.19 & -0.04 & -0.03 & -0.06 & -0.03 \\
\hline & & $\mathrm{H} 1$ & $\mathrm{H} 2$ & $\mathrm{H} 3$ & $\mathrm{H} 4$ & H5 & H6 \\
\hline Brij P-35 & $\delta / \mathrm{ppm}$ & 3.69 & 3.62 & 3.46 & 1.57 & 1.29 & 0.9 \\
\hline \multirow{3}{*}{ Brij P-35+1 } & $\delta / \mathrm{ppm}$ & 3.71 & 3.59 & 3.45 & 1.57 & 1.29 & 0.9 \\
\hline & $\Delta \delta / \mathrm{ppm}$ & -0.02 & 0.03 & -0.01 & 0 & 0 & 0 \\
\hline & & $\mathrm{N}\left(\mathrm{CH}_{3}\right)_{3}{ }^{+}$ & $\alpha-\mathrm{CH}_{2}$ & $\beta-\mathrm{CH}_{2}$ & $\gamma-\mathrm{CH}_{2}$ & Bulk & $\omega-\mathrm{CH}_{3}$ \\
\hline CTAC & $\delta / \mathrm{ppm}$ & 3.38 & 3.48 & 1.68 & 1.29 & 1.20 & 0.83 \\
\hline \multirow[t]{3}{*}{$\mathrm{CTAC}+2$} & $\delta / \mathrm{ppm}$ & 3.69 & 3.29 & 1.73 & 1.33 & 1.26 & 0.86 \\
\hline & $\Delta \delta / \mathrm{ppm}$ & -0.32 & 0.19 & -0.05 & -0.04 & -0.06 & -0.03 \\
\hline & & $\alpha-\mathrm{CH}_{2}$ & $\beta-\mathrm{CH}_{2}$ & Bulk & $\omega-\mathrm{CH}_{3}$ & & \\
\hline SDS & $\delta / \mathrm{ppm}$ & 4.04 & 1.69 & 1.31 & 0.90 & & \\
\hline \multirow[t]{2}{*}{$\mathrm{SDS}+\mathbf{3}$} & $\delta / \mathrm{ppm}$ & 4.03 & 1.67 & 1.29 & 0.89 & & \\
\hline & $\Delta \delta / \mathrm{ppm}$ & 0.01 & 0.02 & 0.02 & 0.01 & & \\
\hline
\end{tabular}

SDS such as $\alpha, \beta, \omega$ and the bulk protons. Similar spectroscopic results have been obtained for solutions of surfactants $\mathrm{SDS}, \mathrm{CTAC}$ and Brij-P35 in $\mathrm{D}_{2} \mathrm{O}$ in the presence of esters 1-3 (see Figures S14-S17 in ESI).

The cross-peaks of the diagnostic aliphatic protons (H-2' and H-18) of 3-acetylestrone (1) and the signals of the surfactant SDS observed in the NOESY contour in Fig. 5a clearly account for the intimate interaction between such protons leading to conclude that 3-acetylestrone (1) is located within the hydrophobic core of the micelle. Furthermore, the fact that the aliphatic proton signals $\left(\mathrm{H}-2^{\prime}\right.$ ad $\mathrm{H}-18)$ interact through space with all the surfactant protons ( $\alpha, \beta, \omega$ and the bulk protons) lead to conclude qualitatively that the estrone derivative (1) is positioned deeply within the hydrophobic core as well as close to the polar shell of the spherical micelle, that is, close to the polar head of the micelle. Indeed, the aromatic protons $(\mathrm{H}-1, \mathrm{H}-2$ and $\mathrm{H}-4)$ clearly showed the nuclear Overhauser effect (NOE) with the $\alpha$ proton of SDS (see Fig. 5b) indicating that the aromatic portion of 3-acetylestrone (1) was mainly positioned close to the polar head of the micelle. Similar conclusions were achieved when 2D NOESY experiments were carried out between 3-acetylestrone (1) and surfactants CTAC and BrijP35, respectively (see Figures S14 and S15 in ESI).

On the other hand, 2D NMR spectroscopy was also used in order to measure some physicochemical properties of the steroid-surfactant complex such as the diffusion coefficient $(D)$ and the hydrodynamic radius $\left(r_{\mathrm{s}}\right)$ performing DOSY experiments which is an analytical technique widely applied in the literature [78-80]. The diffusion is a process that arises from the random motion of molecules as well as steroid-surfactant complex in solution and can be quantitatively measured through the diffusion coefficient $(D)$. Furthermore, the $D$ parameter is inversely related to the mean average micelle radius $\left(r_{\mathrm{s}}\right)$ which is also known as the hydrodynamic radius of such complex (steroid-surfactant complex) according to the Stokes-Einstein relationship in terms of Eq. (4),

$D=\frac{k T}{6 \pi \eta r_{s}}$,

where $k$ is the Boltzman constant, $T$ is the absolute temperature of the system under study and $\eta$ is the viscosity of the solvent. Therefore, knowing the diffusional coefficient $D$, the hydrodynamic radius can be easily calculated.

The diffusional coefficient $D$ can be used to discriminate different components that are present in a mixture because each component is characterized by their own $D$ parameter. However, if the mixture is constituted by two components and these components are aggregated like a complex, it is 

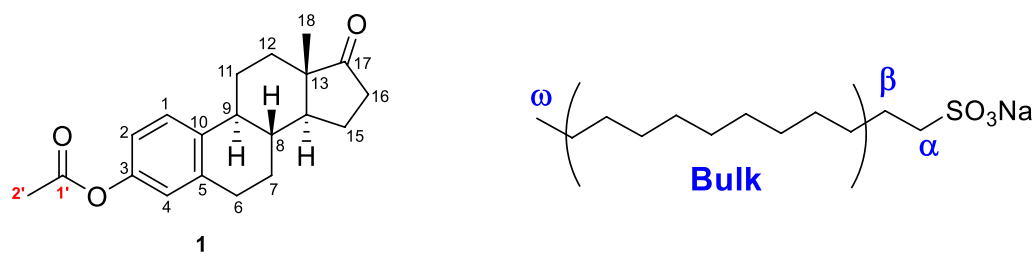

(a) Aliphatic interactions.

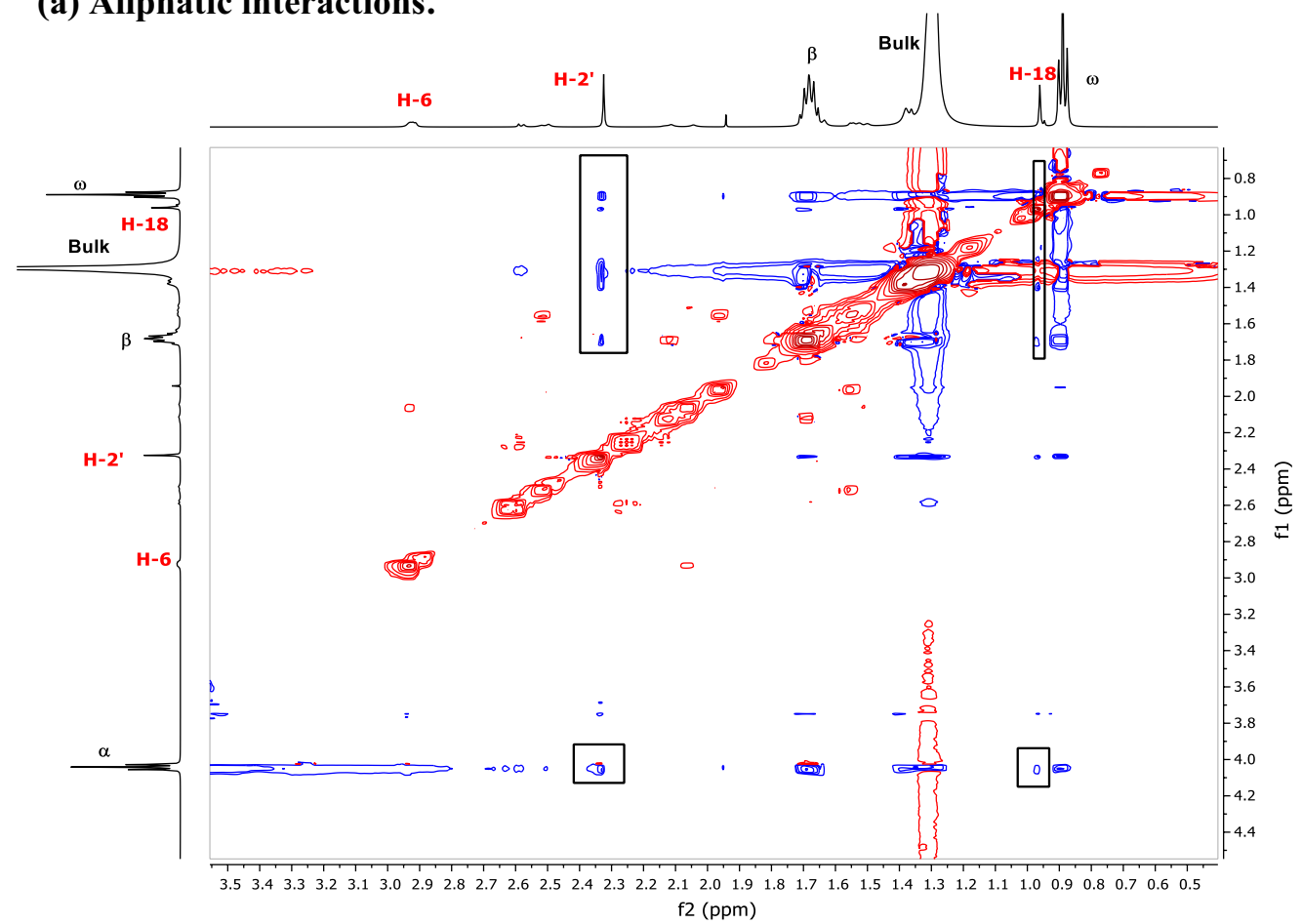

(b) Aromatic interactions.

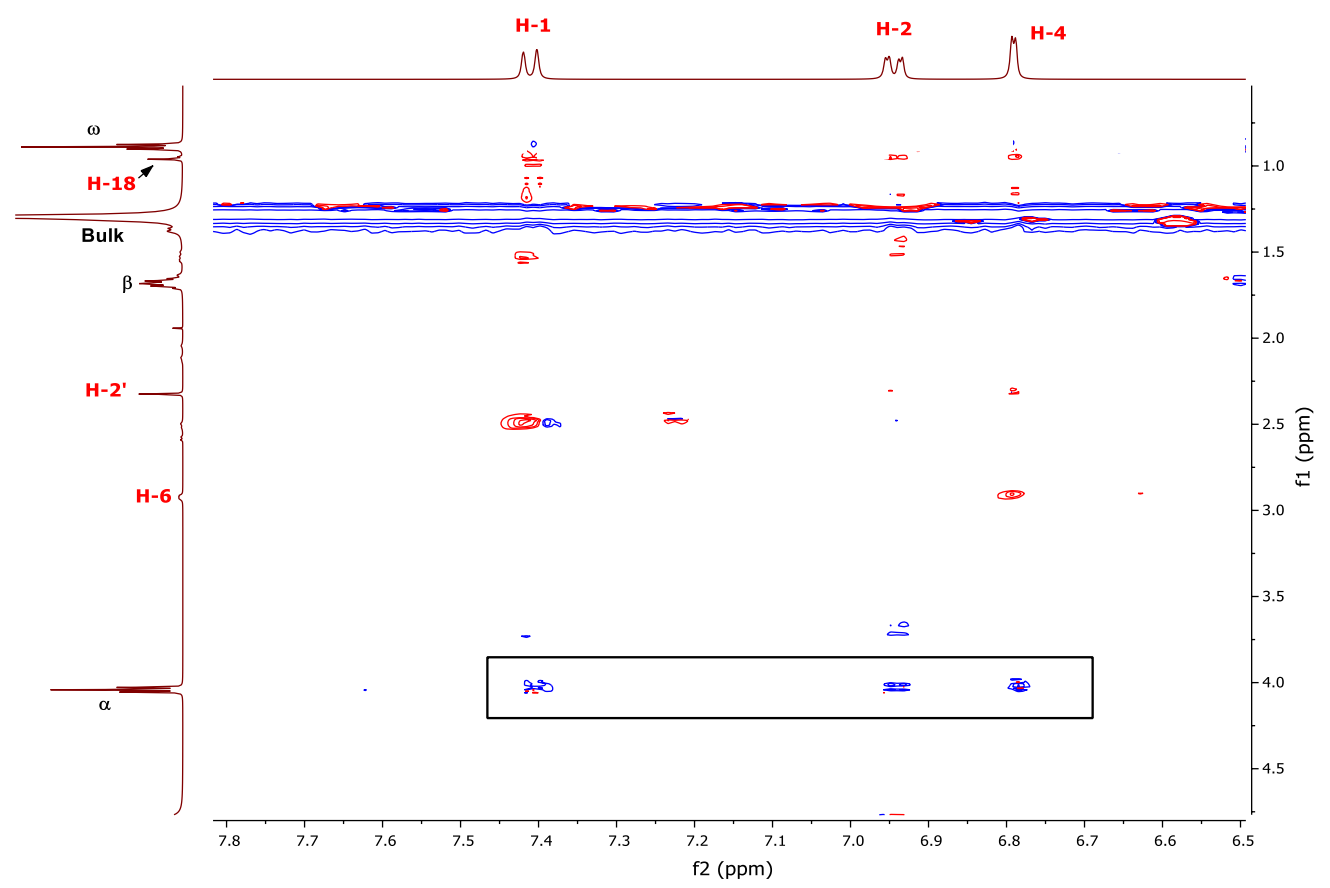


4 Fig. 5 2D NOESY contour plot of a solution of SDS $(50 \mathrm{mM})$ and 3-acetylestrone $(50 \mathrm{mM})$ in $\mathrm{D}_{2} \mathrm{O}$ at room temperature was recorded with a $500 \mathrm{MHz}$ spectrometer

expected that this new entity displays a single diffusional coefficient $D$ [78].

Therefore, with the aim of measuring the diffusional coefficient $D$ and calculate the hydrodynamic radius $r_{\mathrm{s}}$ of a SDS $(0.106 \mathrm{M})$ micellar solution in the presence of 3-acetylestrone (1) a DOSY experiment was carried out in $\mathrm{D}_{2} \mathrm{O}$ and the contour plot thus obtained is depicted in Fig. 6.

As is apparent from Fig. 6, some 3-acetylestrone (1) proton signals $(\mathrm{H}-1, \mathrm{H}-2, \mathrm{H}-4, \mathrm{H}-6, \mathrm{H}-2$ ' and $\mathrm{H}-18)$ as well as the proton signals of the surfactant $\operatorname{SDS}(\alpha, \beta$, bulk and $\omega)$ diffuse like a unique entity with a diffusional coefficient $D$ of $6.90 \times 10^{-11} \mathrm{~m}^{2} \mathrm{~s}^{-1}$. The red dashed line depicted in the figure helps to make visible such idea of unique entity leading to conclude that 3-acetylestrone is located within the hydrophobic core of SDS micelle. Furthermore, DOSY experiments were also carried out with solutions of SDS in $\mathrm{D}_{2} \mathrm{O}$ of different concentration such as $5.20 \mathrm{mM}$ and $0.106 \mathrm{M}$, respectively, and the DOSY contour plots are shown in Figures S18 and S19 (see ESI). The first one has a surfactant concentration that is lower than the $c m c(8.5 \mathrm{mM})$ and a $D$ value of $1.87 \times 10^{-10} \mathrm{~m}^{2} \mathrm{~s}^{-1}$ was obtained which indicates that the surfactant SDS is in the typically monomer form [79]. The solution of SDS displaying a concentration of $0.106 \mathrm{M}$ which is higher than $\mathrm{cmc}$ brings a $\mathrm{D}$ value of $7.17 \times 10^{-11} \mathrm{~m}^{2} \mathrm{~s}^{-1}$ which was attributed to the structurally spherical micelle [80] showing a value similar to that measured in the presence of 3-acetylestrone (1) (compare $7.17 \times 10^{-11} \mathrm{~m}^{2} \mathrm{~s}^{-1}$ with $6.90 \times 10^{-11} \mathrm{~m}^{2} \mathrm{~s}^{-1}$ ).

Next, the hydrodynamic radius $r_{\mathrm{s}}$ was easily calculated from the measured diffusional coefficients $D$ according to Eq. 4 and using the Boltzman's constant $k$ of $1.38 \times 10^{-23} \mathrm{~J} / \mathrm{K}$, the system temperature of $298.15 \mathrm{~K}$ and the water viscosity $\eta$ of $8.90 \times 10^{-4} \mathrm{~Pa} \mathrm{seg}^{-1}$. Thus, the $r_{\mathrm{s}}$ value for SDS $(0.106 \mathrm{M})$ solution was $3.42 \mathrm{~nm}$ while for the SDS solution in the presence of 3-acetylestrone (1) the $r_{\mathrm{s}}$ value was $3.55 \mathrm{~nm}$. Although the hydrodynamic radius values are of the same order of magnitude, it is clear from the data that the SDS micellar solution in the presence of 3-acetylestrone (1) shows a $r_{\mathrm{s}}$ value slightly higher than the $r_{\mathrm{s}}$ value of the same solution but in the absence of the steroid suggesting that ester $\mathbf{1}$ is located within the SDS micelle.

The cross-peaks of diagnostic signals observed in the 2D NMR (NOESY experiments) contour plots are in agreement with and reinforce the UV-visible spectroscopic analyses as well as the differential chemical shifts $(\Delta \delta)$ studies. Furthermore, the 2D NMR (DOSY experiments) contour plots bring the information that the surfactant solution in the presence of the esters behaves like a unique entity with a single diffusional coefficient $D$ leading to conclude that the ester is located within the hydrophobic core of the micelle. However, at this moment we cannot estimate precisely the location of esters 1-3 with accuracy but we can suggest that the esters are located within the hydrophobic core of the micelle because the proton nuclei of the esters correlate nicely with the proton nuclei of the surfactant as can be seen through the cross-peaks of the NOESY contour plots and a single diffusional coefficient $D$ from the DOSY contour plots.

\section{Discussion}

The results described above demonstrated that 3-acetyl- and 3-benzoyl estrone, $\mathbf{1}$ and $\mathbf{2}$, respectively, reacted efficiently upon direct irradiation $(254 \mathrm{~nm})$ in micellar media (SDS, Brij-P35 and CTAC) under $\mathrm{N}_{2}$ atmosphere (see Scheme 2 and Fig. 1) providing the ortho-regioisomers $\mathbf{1 a}$ and $\mathbf{1 b}$ from ester $\mathbf{1}$ and $\mathbf{2 a}$ and $\mathbf{2 b}$ from ester $\mathbf{2}$, along with estrone $\mathbf{4}$ (see Table 1). Furthermore, during the irradiation of 3-acetyl estrone (1) in micellar solutions epimerization reaction of regioisomer 1a to give compound $\mathbf{5}$ occurred whereas no epimerization of estrone (4) into lumiestrone (6) was observed upon irradiation of 3-benzoyl estrone (2) in micellar media. Therefore, this photochemical behaviour leads to propose that two reaction pathways operate during the irradiation of 3-acylestrone: (1) the photo-Fries rearrangement reaction and, (2) the Norrish type I reaction. Based on the results obtained in this work, a reaction mechanism for the irradiation of 3-acylestrone is proposed in Scheme 5.

Thus, irradiation of 3-acylestrone (1 and $\mathbf{2}$ ) with light of $254 \mathrm{~nm}$ populates efficiently the photo reactive excited state which is the singlet excited state. The triplet excited state of the esters is not involved in the photo-Fries rearrangement as it was previously demonstrated through triplet quenching experiments $[59,60]$. Then, homolytic fragmentation of the ester group (path (a)) occurs efficiently from the singlet excited state within the hydrophobic core of the micelle and competitive radiative and radiationless processes from the same excited state takes place $\left(k_{d}\right)$. After $\mathrm{C}(\mathrm{O})-\mathrm{O}$ bond cleavage, the acyl and phenoxy radicals are formed within the micellar core and these species evolve exclusively to the ortho-regioisomers (1a, $\mathbf{1 b}$ from ester $\mathbf{1}$ and $\mathbf{2 a}$ and $\mathbf{2 b}$ from ester 2) through a [1;3]-migration of the acyl group (paths (b) in Scheme 5). Furthermore, no significant amounts of estrone (4) were detected upon irradiation of esters $\mathbf{1}$ and $\mathbf{2}$ under micellar solution because the confined media inhibits the diffusion of the radical species from the hydrophobic core of the micelle to the bulk (path (c)). However, the very low quantities of estrone (4) detected in the photolyzed solution can be attributed to the hydrogen atom abstraction of the phenoxy radical from the aliphatic chains of the surfactant.

On the other hand, upon irradiation of ester 1 in micellar media it was found that regioisomer 1a undergoes 


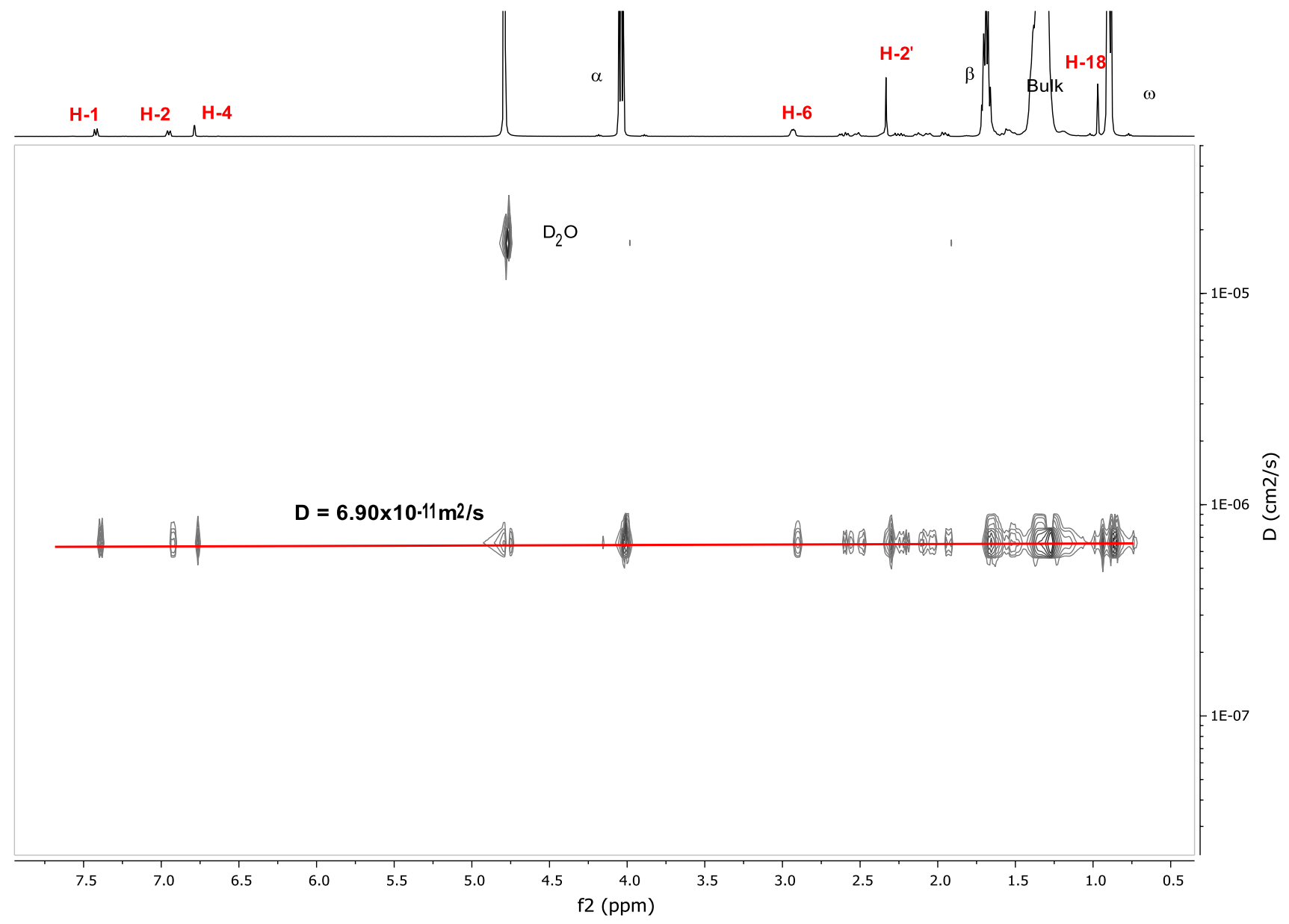

Fig. 6 2D DOSY plot of a solution of $\operatorname{SDS}(0.106 \mathrm{M})$ in $\mathrm{D}_{2} \mathrm{O}$ in the presence of 3-acetylestrone (saturation) at room temperature was recorded with a $500 \mathrm{MHz}$ spectrometer

photo-epimerization reaction to afford compound $\mathbf{5}$ due to the out-of-plane deviation of the acetyl group from the planarity of the aromatic ring where the excited state intramolecular proton transfer process (ESIPT) [61-65] and the cis-trans keto tautomerism were disfavored (see Scheme $4 b$ ). Regioisomer 1a is a good chromophore capable to absorb UV light of $254 \mathrm{~nm}$ and populates the triplet excited state of the carbonyl group (C-17) at the D ring of the steroid because a singlet-singlet energy transfer between the aryl moiety and the carbonyl group (C-17) occurred efficiently (see Scheme 4b) [81]. Once the triplet excited state was formed, two competitive pathways occurs, viz. deactivation of the triplet state through radiationless process $\left(k{ }_{d}{ }_{d}\right.$ in Scheme 5) that restores $1 \mathbf{a}$ in the ground state and a Norrish Type I photoreaction (path (d) in Scheme 5). Thus, a biradical intermediate within the hydrophobic core of the micelle is formed because a homolytic fragmentation of the $\mathrm{C} \alpha-\mathrm{C}=\mathrm{O}$ bond at the ring $\mathrm{D}$ of compound 1a (path (d)) takes place efficiently. Then, the biradical intermediate epimerizes the methyl group at C-13 giving compound $\mathbf{5}$ (path (e)) [18, 69, 82-85]. This photochemical behavior, where the triplet excited state located on the carbonyl group (C-17) of the D ring of the steroid as the photo reactive state is involved in the photoinduced epimerization reaction, has been previously observed in homogeneous media [22].

Furthermore, it was found that ortho-regioisomers $\mathbf{1 b}$, 2a and $\mathbf{2 b}$ were photo stable upon irradiation with UV light $(\lambda=254 \mathrm{~nm})$. ESIPT process between the proton of the hydroxy group and the carbonyl group attached to the aromatic ring of such regioisomers (see Scheme 4) and a cis-trans keto tautomerism that proceeds efficiently accounts for the strong photo stability. During this sequence of events radiationless processes are the sole deactivation pathways of the ortho-regioisomers and consequently, no photoinduced epimerization was observed for these compounds. However, compound 1a undergoes photo-epimerization reaction resulting in compound 5 because the out-of-plane deviation of the acetyl group from the planarity of the aromatic ring disfavors the intramolecular proton transfer process and the cis-trans keto tautomerism. 


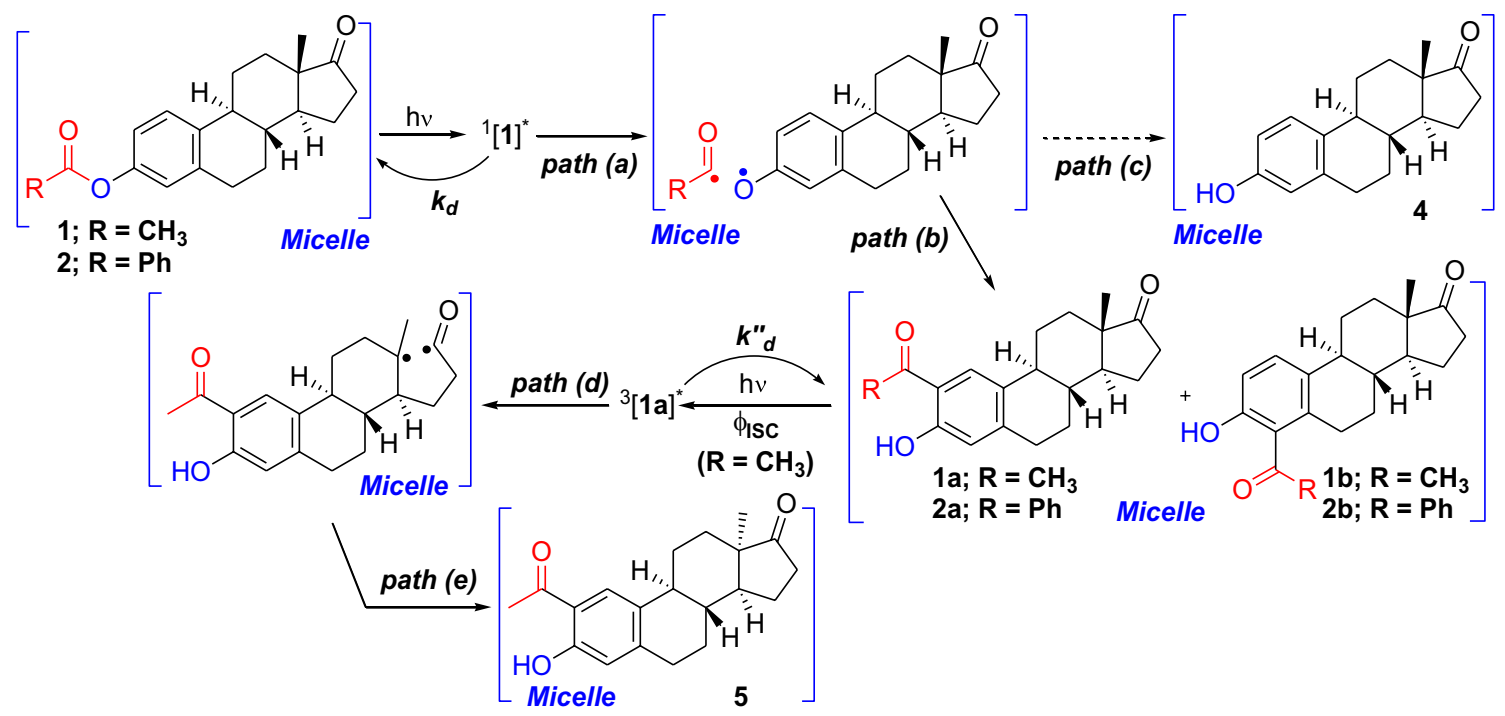

Scheme 5 Proposed reaction mechanism of the photo-Fries rearrangement of esters $\mathbf{1}$ and $\mathbf{2}$ micellar solutions

Direct irradiation of 3-acetyl-17-norestrone (3) with light of $254 \mathrm{~nm}$ in micellar media gave the expected ortho-regioisomers 3a and $\mathbf{3 b}$ but no 17-norestrone (7) was detected in the photolyzed solution (see Table 2). This noticeable selectivity in favor of the formation of the regioisomers was attributed to the exclusively effect of the confined micellar media on the photoreaction. In fact, micelles can be considered as microreactor vessel that are able to inhibit the diffusion of the radical species generated within the hydrophobic core of the micelle upon irradiation of ester 3 . Then, the phenoxy radical did not escape from the micellar core and consequently, 17-norestrone is not formed. This interesting micellar behavior was not observed in homogeneous media such as cyclohexane because 17-norestrone was detected in the photolyzed reaction due to a free diffusion of the radical species into the bulk. Furthermore, no competitive Norrish Type I reaction of ortho-regioisomers $\mathbf{3 a}$ and $\mathbf{3 b}$ and 17-norestrone (7) was observed because no carbonyl group at $\mathrm{C}-17$ is present in their structures. Then, the photo-Fries reaction of ester $\mathbf{3}$ occurred smoothly with quantum yields $\left(\phi_{\mathrm{R}}\right)$ that are similar to those obtained upon irradiation of esters $\mathbf{1}$ and $\mathbf{2}$. These values are lower than 0.06 indicating that radiationless deactivation process of the photo reactive excited state competes significantly with the photochemical reaction pathway.

The noticeable selectivity induced by the micelles on the product distribution of the photo-Fries rearrangement of ester $\mathbf{1}, \mathbf{2}$ and $\mathbf{3}$ is due to the possible location of the esters within the hydrophobic core of the confined media. Thus, UV-visible spectroscopy was carried out to determine the binding constants $K_{\mathrm{b}}$ between the esters and the surfactants. Double-reciprocal plots (see Fig. 3 and Figure S8 in ESI) led to obtain from the intercept to slope ratio the $K_{\mathrm{b}}$ values (see Table 3) that are typical values of steroids indicating that the esters $\mathbf{1}-\mathbf{3}$ are solubilized efficiently within the hydrophobic core of the micelles. This behavior was also corroborated using NMR spectroscopy. In fact, the NMR spectra of the surfactants in the absence and in the presence of the esters were recorded in $\mathrm{D}_{2} \mathrm{O}$ and upfield/downfield perturbations of the surfactants' proton chemical shifts due to the presence of the esters were quantified through the differential chemical shift $(\Delta \delta)$ values (see Table 4 and Fig. 4). In all the cases analyzed these magnitudes are much above the value for typical errors in the chemical shifts $(\sim 0.002 \mathrm{ppm})$ suggesting that the esters are located within the hydrophobic core of the micelles as well as the shell of the surfactant micelles favoring the intimate interaction of the esters with all the proton nuclei of the hydrocarbon chains of the surfactant.

Furthermore, application of 2D NMR spectroscopy in terms of NOESY experiments led to the qualitatively confirmation of the location of esters 1-3 within the hydrophobic core of the micelle. Cross-peaks between diagnostic signals of the esters and the surfactants, respectively, are noticed in the contour plots (see Fig. 5) suggesting that the esters are located within the micelle because the proton nuclei of the esters correlate nicely with the proton nuclei of the surfactant. Also, these nice correlations are in agreement with and reinforce the UV-visible spectroscopic analyses as well as the differential chemical shifts $(\Delta \delta)$ studies. However, precise and accurate estimation of the location of the esters 1-3 within the micelle is not possible. 


\section{Conclusion}

The photo-Fries rearrangement reaction of esters $\mathbf{1 - 3}$ in micellar solution examined in this paper takes place efficiently providing the expected ortho-regioisomers with a noticeable selectivity due to the inhibition of the formation of estrone (or 17-norestrone in the case of ester 3 ) in the confined media. The $\mathrm{C}-\mathrm{O}$ homolytic cleavage of the ester group occurs from the singlet excited state giving acyl and phenoxyl radicals within the hydrophobic core of the micelle and competes with radiative and radiationless deactivation pathways. These radical species are coupled within the micelle to give the desired ortho-regioisomers $(\mathbf{1 a}, \mathbf{1 b}, \mathbf{2 a}$, $\mathbf{2 b}, \mathbf{3 a}$ and $\mathbf{3 b}$ in Scheme 2) through a [1;3]-acyl migration process but they cannot diffuse to the bulk and estrone (5) and 17-norestrone (7) are not formed. Ortho-regioisomers 1b, 2a and $\mathbf{2 b}$ were found to be photo stable compounds due to the efficient ESIPT processes under UV irradiation (see Scheme 4) whereas ortho-regioisomer (1a) is found to epimerize upon irradiation with UV light $(254 \mathrm{~nm})$ through a Norrish Type I mechanism (see Schemes 4 and 5). The epimerization photoreaction involves the triplet excited state of the carbonyl group (C-17) at the D ring of the steroids that is populated from the singlet excited state of the phenolic moiety through an intramolecular energy transfer process. On the other hand, the binding constants $\left(\mathrm{K}_{\mathrm{b}}\right)$ between esters 1-3 were measured using UV-visible spectroscopy and the values are those expected for the solubilization of steroids within the surfactant solutions (see Table 3). The differential chemical shifts $(\Delta \delta)$ were calculated from the NMR spectra of the surfactant in the absence and in the presence of the esters and noticeable perturbation of the proton nuclei of the surfactant was thus observed. 2D NMR spectroscopy in terms of NOESY experiments led to the qualitatively confirmation of the location of esters 1-3 within the hydrophobic core of the micelle through cross-peaks between diagnostic signals of the esters and the surfactants in the contour plots (see Fig. 5). Further studies on the photo-Fries rearrangement reaction of 3-alkyl and 3-arylsulfonyloxyestrone derivatives in micellar media are currently in progress in our laboratory and will be reported in due course.

\section{Experimental section}

\subsection{Material and equipment}

The steroids 3-acetylestrone, 3-benzoylestrone and 3-acetyl17-norestrone have been previously prepared [22]. Surfactants DSD, Brij-P35 and CTAC were purchased from Aldrich and Fluka and were used without further purification. Spectrograde cyclohexane was obtained from J. T.
Baker and was used as received. Deionized water (MilliQ) was used to prepare the stock aqueous solutions of the surfactants. ${ }^{1} \mathrm{H}$ NMR spectra were registered using a BrukerAC-500 spectrometer in $\mathrm{CDCl}_{3}$; chemical shifts $(\delta)$ are reported in parts per million (ppm), relative to internal tetramethylsilane. 2D NOESY spectra were registered in the same spectrometer in $\mathrm{D}_{2} \mathrm{O}$; chemical shifts $(\delta)$ are reported in parts per million ( $\mathrm{ppm})$, relative to internal trimethylsilylpropionic acid. The measurements were carried out using standard pulse sequences. The UV-visible spectra were measured using a Shimadzu UV-1203 spectrophotometer. All the measurements were made using $1 \mathrm{~cm}$ stoppered quartz cells at $298 \mathrm{~K}$.

\subsection{Determination of the constants of binding $\left(K_{b}\right)$ of steroids 1-3 in micellar media}

Solutions of 3-acetylestrone (1), 3-benzoylestrone (3) and 3-acetyl-17-norsestrone (3) were prepared in deionized water (MilliQ) and their concentration varied between $5.5 \times 10^{-5} \mathrm{M}$ and $1.0 \times 10^{-4} \mathrm{M}$. An aliquot $(2 \mathrm{~mL})$ of the steroid solution was placed in a two-faced stoppered quartz cuvette provided with a stir bar and the UV-visible spectrum was registered, then the $A_{0}$ value at the maximum wavelength was read. Next, aliquots of concentrated surfactant solution $(10 \mu \mathrm{L})$ were added successively and the $\mathrm{UV}$-visible spectra were registered taking for each solution the $A$ value at the maximum wavelength. After each addition of surfactant solution, the resulting solution was stirred for $20 \mathrm{~min}$. With the values of $A_{0}$ and $A$ in hand, plots of $\left(A_{0} /\left(A-A_{0}\right)\right)$ versus the reciprocal of the concentration of the surfactants were created and the data were fitted with a linear regression program provided by SigmaPlot version 11.0. From the ratio of the slope and the origin it was easy to calculate the $K_{\mathrm{b}}$ values.

\subsection{Photoirradiations}

\subsubsection{General procedure}

Photoirradiations of esters 1-3 in homogeneous media Stock solutions of steroids $\mathbf{1}-\mathbf{3}(0.106 \mathrm{mmol})$ in cyclohexane $(100 \mathrm{~mL})$ were prepared. An aliquot $(65 \mathrm{~mL})$ was placed in a stoppered Erlenmeyer quartz flask $(100 \mathrm{~mL})$ and was degassed with argon for $30 \mathrm{~min}$. The flask was placed in a homemade optical bench which provided the possibility to use eight lamps. The solutions of the steroids were stirred during the irradiation process. Irradiations with $\lambda_{\text {exc }}=254 \mathrm{~nm}$ were carried with eight germicidal lamps (Philips, each of 20 Watts, purchased in Argentina). The progress of the reaction was monitored using TLC [eluent: hexane-ethyl acetate (8: $2 \mathrm{v} / \mathrm{v})$; spots were visualized with UV light (254 and $366 \mathrm{~nm}$ ) and with $\mathrm{I}_{2}$ ]. When the conversion 
of the starting material was higher than $90 \%$, the photolyzed solution was evaporated carefully to dryness under reduced pressure. The yellowish solid residue obtained was dissolved in $\mathrm{CDCl}_{3}$ and the ${ }^{1} \mathrm{H}$ NMR spectra were recorded.

Photoirradiations of esters 1-3 in micellar media Stock solutions of surfactants in deionized water (MilliQ) were freshly prepared and the concentrations of these solutions were: SDS 0.10 M; CTAC 0.02 M and Brij-P35 0.05 M. A slight excess of 3-acylestrone derivatives (1-3) was placed in a stoppered quartz cell provided with a stir bar $(3 \mathrm{ml})$ and the surfactant stock solution $(2 \mathrm{~mL})$ was added. After mixing at $25^{\circ} \mathrm{C}$ for $96 \mathrm{~h}$, the suspension was filtered through a membrane with $0.4 \mu \mathrm{m}$ diameter pores to remove a small amount of the undissolved steroid. The final concentration of the substrates in all cases was of the order of $10^{-3} \mathrm{M}$. The quartz cell was placed in a homemade optical bench equipped with two germicidal lamps (Philips, each of 20 Watts, purchased in Argentina). The progress of the photoreaction was monitored by three different methods: (1) UV-visible spectroscopy; (2) TLC [eluent, hexane-ethyl acetate $(8: 2 \mathrm{v} / \mathrm{v})$; spots were visualized with UV light $(254$ and $366 \mathrm{~nm}$ ) and with cerium molybdate stain (Hanessian's stain)]; and (3) ${ }^{1} \mathrm{H}$ NMR spectroscopy.

The conversion of the esters was kept below 50\% to avoid secondary reactions and the formation of by-products. Finally, the photolyzed solutions were diluted with $2 \mathrm{~mL}$ of an aqueous solution of $\mathrm{NaCl}$ and then extracted with ethyl acetate $(3 \times 2 \mathrm{~mL})$ while the system was carefully shaken. The organic layer was separated, dried over $\mathrm{Na}_{2} \mathrm{SO}_{4}$ and evaporated to dryness under vacuum. The solid residue was dissolved in deuterated chloroform and the ${ }^{1} \mathrm{H}$ NMR spectra was recorded. The relative yields were calculated using aromatic protons of the steroid derivatives as the diagnostic signals taking into account that the fully characterization of all the photoproducts obtained from the irradiation of 3 -acylestrone derivatives have been previously reported [22].

Supplementary Information The online version contains supplementary material available at https://doi.org/10.1007/s43630-021-00107-w.

Acknowledgements SMB and JAR are research members of CONICET. MIQ thanks CONICET for doctoral scholarship

(Doctorate Program).

\section{Declarations}

Conflict of interest On behalf of all authors, the corresponding author states that there is no conflict of interest.

\section{References}

1. Lian, L., Miao, Ch., Hao, Zh., Liu, L., \& Q. Y., Song, W., \& Yan, Sh. . (2021). Reevaluation of the contributions of reactive intermediates to the photochemical transformation of $17 \beta$-estradiol in sewage effluent. Water Research, 189, 116633.

2. Perondi, T., Michelon, W., Basso, V., Bohrer, J. K., Viancelli, A., Fonseca, T. G., Treichel, H., Moreira, R. F. M., Peralta, R. A., Düsman, E., \& Pokrywiecki, T. S. (2020). Degradation of estriol (E3) and transformation pathways after applying photochemical removal processes in natural surface water. Water Science and Technology, 82, 1445-1453.

3. Perondi, T., Michelon, W., Junior, P. R., Knoblauch, P. M., Chiareloto, M., Moreira, R. F. P. M., Moreira, R. A., Düsman, E., \& Pokrywiecki, T. S. (2020). Advanced oxidative processes in the degradation of $17 \beta$-estradiol present on surface waters: Kinetics, byproducts and ecotoxicity. Environmental Science and Pollution Research, 27, 21032-21039.

4. Reng, D., Chen, F., Ren, Zh., \& Wang, Y. (2019). Different response of 17- $\alpha$-ethinylestradiol photodegradation induced by acquatic humic and fulvic acids to typical water matrixes. Process Safety and Environmental Protection, 121, 367-373.

5. Cantalupi, A., Maraschi, F., Pretali, L., Albini, A., Nicolis, S., Ferri, E. N., Profumo, A., Speltini, A., \& Sturini, M. (2020). Glucocorticoids in freshwaters: Degradation by solar light and environmetal toxicity. International Journal of Environmental Research and Public Health, 17, 8717-8732.

6. Cacciari, R. D., Reynoso, E., Menis Candela, F., Sabini, C., Montejano, H. A., \& Biasutti, M. A. (2020). Photochemical study of the highly used corticosteroids dexamethansone and prednisone. Effects of micellar confinement and cytotoxicity analysis of photoproducts. New Journal of Chemistry, 44, 18119-18129.

7. Vulliet, E., Falletta, M., Marote, P., Lomberget, T., Païssé, J. O., \& Grenier-Loustalot, M. F. (2010). Light induced degradation of testosterone in waters. Science of the Total Environment, 408, 3554-3559.

8. Young, R. B., Lotch, D. E., Mawhinney, D. B., Nguyen, T. H., Davis, J. C. C., \& Borch, T. (2013). Direct photodegradation of androstenedione and testosterone in natural sunlight: Inhibition by dissolved organic matter and reduction of endocrine disrupting potential. Environmental Science \& Technology., 47, 8416-8424.

9. Vulliet, E., Giroud, B. B., \& Marote, P. (2013). Determination of testosterone and its photodegradation products in surface waters using solid-phase extraction followed by LC-MS/MS analysis. Environmental Science and Pollution Research, 20, 1021-1030.

10. Waters, J. A., Kondo, Y., \& Witkop, B. (1972). Photochemistry of steroids. Journal of Pharmaceutical Sciences, 61, 321-334.

11. Karkas, M. D., Porco, J. A., \& Stephenson, C. R. J. (2016). Photochemical approaches to complex chemotypes: Applications in natural product synthesis. Chemical Reviews, 116, 9683-9747.

12. Pflug, N. C., Kral, A. K., Hankard, M. K., Breuckman, K. C., Kolodziej, E. P., Gloer, J. B., Wammer, K. H., \& Cwiertny, D. M. (2020). Photolysis of trenbolone acetate metabolites in the presence of nucleophiles: Evidence for metastable photoaddition products and reversible associations with dissolved organic matter. Environ. Science \& Technology, 54, 12181-12190.

13. Capilato, J. N., Pitts, C. R., Rowshanpour, R., Dubbing, T., \& Lectka, T. (2020). Site-selective photochemical fluorination of ketals: Unanticipated outcomes in selectivity and stability. Journal of Organic Chemistry, 85, 2855-2864.

14. Dighe, S. U., Juliá, F., Luridiana, A., Douglas, J. J., \& Leonori, D. (2020). A photochemical dehydrogenative strategy for aniline synthesis. Nature, 584, 75-81.

15. Laktsevich-Iskryk, M. V., Rudovich, A. S., Zhabinskii, V. N., Khripach, V. A., \& Hurski, V. A. (2020). A photochemical approach to 18-nor-17 $\beta$-hydroxymethyl-17 $\alpha$-methylandrost-13ene steroids. Steroids, 159, 108652.

16. Tiver, S., \& Yates, P. (1988). Photochemistry of cyclic $\alpha$-hydroxy ketones. I. The nature and genesis of the photoproducts from 
steroidal 5-hydroxy 6-keto steroids and related compounds. Canadian Journal of Chemistry, 66, 214-226.

17. Bellus, D., Kearns, D. R., \& Schaffner, K. (1969). Photochemische reaktionen. 52. Mitteilung [1]. ZurPhotochemie von $\alpha, \beta$-u ngesättingtencyclishenketonen: Spezifische reaktionen der $\mathrm{n}, \pi^{*}$ und, $\pi^{*}$-triplettzutstände von $O$-acetyl-tetosteron und 10-methyl$\Delta$ 1,9-octalon-(2). Helvetica Chimica Acta, 52, 971-1009.

18. Wu, Z.-Z., \& Morrison, H. (1992). Organic photochemistry. 95. Antenna-initiated photochemistry of distal groups in polyfunctional steroids. Intramolecular singlet and triplet energy transfer in 3 $\alpha$-(dimethylphenylsiloxy)-5 $\alpha$-androstan-17-one and $3 \alpha$-(dimethylphenylsiloxy)-5 $\alpha$-androstane-11,17-dione. Journal of the American Chemical Society, 114, 4119-4128.

19. Blandon, P., McMeekin, W., \& Williams, I. A. (1963). Steroids Derived from Hecogenin. Part III. The Photochemistry of Hecogenin Acetate. Journal of the Chemical Society, 5727-5737

20. Jeger, O., \& Schaffner, K. (1970). On photochemical transformations of steroids. Pure and Applied Chemistry, 20, 247-262.

21. Lai, W.-C., Danko, B., Csabi, J., Kele, Z., Chang, F. R., Pascu, M. L., Gati, T., Simon, A., Amaral, A. L., Toth, G., \& Hunyadi, A. (2014). Rapid, laser-induced conversion of 20-hydroxyecdysone. Follow-up study on the products obtained. Steroids, 89, 56-62.

22. Quindt, M. I., Gola, G. F., Ramirez, J. A., \& Bonesi, S. M. (2019). The photo-Fries rearrangement of some 3-acylestrone in homogeneous media. Preparative and mechanistic studies. Journal of Organic Chemistry, 84, 7051-7065.

23. Quindt, M. I., Gola, G. F., Ramirez, J. A., \& Bonesi, S. M. (2021). Photochemical behavior of some estrone aryl and methyl sulfonates in solution. Preparative and mechanistic studies. Photochemistry and Photobiology, 97, 8-21.

24. Fan, J., Zheng, Y., Yang, Y., Du, L., \& Wang, Y. (2020). Enhancement of ultraviolet B irradiation with a photoluminiscent composite film and its application in photochemical microfluidic synthesis. Industrial and Engineering Chemistry Research, 59, 12870-12878

25. Sheng, X., Zheng, Y., Li, W., Gao, R., Du, L., \& Wang, Y. (2020). Scale-up potential of photochemical microfluidic synthesis by selective dimension enlarging with agitation of microbubbles. Chemical Engineering Science, 226, 5862.

26. Niu, W., Zheng, Y., Li, Y., Du, L., \& Liu, W. (2021). Photochemical microfluidic synthesis of vitamin D3 by improved light sources with photoluminiscent substrates. Chinese Journal of Chemical Engineering, 29, 204-211.

27. Tung, C. H., Wu, L. Z., Zhang, L. P., \& Cheng, B. (2003). Supramolecular systems as microreactors: control of product selectivity in organic phototransformation. Accounts of Chemical Research, 36, 39-47.

28. Liu, R. S. H., \& Hammond, G. S. (2005). Reflection on medium effects on photochemical reactivity. Accounts of Chemical Research, 38, 396-403.

29. Miranda, M. A., \& Galindo, F. (2003). Photochemistry of Organic Molecules in isotropic and Anisotropic Media. In V. Ramamurthy \& K. S. Schanze (Eds.), Chapter 2: The Photo-Fries rearrangement (pp. 43-131). New York: Marcel Dekker.

30. Natarajan, A., Kaanumale, L. S., \& Ramamurthy, V. (2004). CRC Handbook of organic photochemistry and photobiology. In W. Horspool \& F. Lenci (Eds.), Manipulating photochemical reactions (pp. 107-147). CRC Press.

31. Turro, N. J. (2000). From boiling stones to smart crystals: supramolecular and magnetic isotope control of radical-radical reactions in zeolites. Accounts of Chemical Research, 33, 637-646.

32. Ramamurthy, V. (2000). Controlling photochemical reactions via confinement: Zeolites. Journal of Photochemistry and Photobiology C: Photochemistry Reviews, 1, 145-166.
33. Fendler, J. H., \& Fendler, E. J. (1975). Catalysis in Micellar and Macromolecular Systems. Academic Press.

34. Holland, P.M. \& Rubingh, D.N. (1992). Mixed Surfactant System. In P. M., Holland \& D. N. Rubingh, (Eds.), Mixed Surfactant System An Overview. (pp. 2-30). American Chemical Society.

35. Gu, W., \& Weiss, R. G. (2001). Extracting fundamental photochemical and photophysical information from photorearrangements of aryl phenylacylates and aryl benzyl ethers in media comprised of polyolefinic films. J. Photochem. Photobiol. C: Photochemistry Reviews, 2, 117-137.

36. Kaanumalle, L. S., Gibb, C. L. D., Gibb, B. C., \& Ramamurthy, V. (2007). Photo-Fries reaction in water made selective with a capsule. Organic \& Biomolecular Chemistry, 5, 236-238.

37. Kulasekharan, R., Choudhurry, R., Prabhakar, R., \& Ramamurthy, V. (2011). Restricted rotation due to the lack of free space within a capsule translates into product selectivity: Photochemistry of cyclohexyl phenyl ketones within a water-soluble organic capsule. Chemical Communications, 47, 2841-2843.

38. Kaanumalle, L. S., Nithyanandhan, J., Pattabiaman, M., Jayaraman, N., \& Ramamurthy, V. (2004). Water-Soluble Dendrimers as Photochemical Reaction Media: Chemical Behavior of Singlet and Triplet Radical Pairs Inside Dendritic Reaction Cavities. Journal of the American Chemical Society, 126, 8999-9006.

39. Menger, F. M. (1979). The structure of micelles. Accounts of Chemical Research, 12, 111-117.

40. Turro, N. J., \& Mattay, J. (1981). Photochemistry of some deoxybenzoins in micellar solutions. Cage effects, isotope effects, and magnetic field effects. Journal of the American Chemical Society, $103,4200-4204$.

41. Turro, N. J., Sidney Cox, G., \& Paczkowski, M. A. (1985). Topics in Current Chemistry, Photochemistry and Organic Synthesis. In F. L. Boschke (Ed.), Photochemistry in Micelles (pp. 57-97). Springer.

42. Kano, K., \& Matsuo, T. (1973). Photochemical reaction of the p-benzoquinones in micellar system. Chemistry Letters, 2, $1127-1132$.

43. Kano, K., Takada, Y., \& Matsuo, T. (1975). Photochemistry in micellar system. II. Photochemical reduction of b-arylquinonesulfonates in the presence of cationic surfactants. Bulletin of the Chemical Society of Japan, 48, 3215-3219.

44. Yasudat, M., Nishinaka, Y., Nakazono, T., Hamasaaki, T., Nakamura, N., Shiragami, T., Pac, C., \& T., \& Shima, K. . (1998). Photochemistry of flavins in micelles: Specific effects of anionic surfactants on the monomerization of thymine cyclobutane dimers photosensitized by tetra- $O$-acyl riboflavins. Photochemistry and Photobiology, 67, 192-197.

45. Souza Santos, M., Morais Del Alma, M. P. F., Ito, A. S., \& Naal, R. M. Z. G. (2014). Binding of chloroquine to ionic micelles: Effect of $\mathrm{pH}$ and micellar surface charge. Journal of Luminescence, 147, 49-58.

46. Iguchi, D., Erra-Balsells, R., \& Bonesi, S. M. (2016). Photo-Fries rearrangement of aryl acetamides: regioselectivity induced by the aqueous micellar green environment. Photochemical \& Photobiological Sciences, 15, 106-116.

47. Siano, G., Crespi, S., Mella, M., \& Bonesi, S. M. (2019). Selectivity in the photo-Fries rearrangement of some aryl benzoates in green and sustainable media. Preparative and mechanistic studies. Journal of Organic Chemistry, 84, 4338-4352.

48. Siano, G., Crespi, S., \& Bonesi, S. M. (2020). Direct irradiation of phenol and p-substituted phenols with a laser pulse $(266 \mathrm{~nm})$ in homogeneous and micro heterogeneous media. A time-resolved spectroscopy study. The Journal of Organic Chemistry, 85(21), 14012-14025.

49. Siano, G., Crespi, S., \& Bonesi, S. M. (2021). Substituent and surfactant effects on the photochemical reaction of some aryl 
benzoates in micellar green environment. Photochemistry and Photobiology. https://doi.org/10.1111/php.13431

50. Anderson, J. C., \& Reese, C. B., (1960). Photoinduced Fries rearrangement. Proc. Chem. Soc.

51. Bellus, D. (1971). Photo-Fries rearrangement and related photochemical [1, j]-shift (j: 3, 5, 7) of carbonyl and sulfonyl groups. Advances in Photochemistry, 8, 109-159.

52. Miranda, M. A. (1995). CRC Handbook of organic photochemistry and photobiology. In W. Horspool \& P. S. Song (Eds.), The Photo-Fries rearrangement (pp. 570-578). CRC Press.

53. Turro, N. J. (1978). In Modern Molecular Photochemistry, Chapter 5 (pp. 76-152). Menlo Park: The Benjamin Cummings Publishing Company.

54. Turro, N. J., Ramamurthy, V., \& Scaiano, J. C., (2010). Modern Molecular Photochemistry of Organic Molecules. In N. J., Turro, V., Ramamurthy, \& J. C., Scaiano (Eds.). Chapter 4 (pp. 169-362). Sausalito: University Science Books.

55. Zakharova, L. Y., Valeeva, F. G., Ibragimova, A. R., Zakharov, V. M., Kudryavtseva, L. A., Elistratova, Yu. G., Mustafina, A. R., Konovalov, A. I., Shtykov, S. N., \& Bogomolova, I. V. (2007). Properties of a sodium dodecyl sulfate-Brij 35 binary micellar system and their effect on the alkaline hydrolysis of $O$-ethyl$O$-p-nitrophenylchloromethylphosphonate. Colloid Journal, 69 , 718-725.

56. Fuguet, E., Rafols, C., \& Rosés, M. (2003). Characterization of the solvation properties of surfactants by solvatochromic indicators. Langmuir, 19, 6685-6692.

57. Reichardt, Ch. (2003). Solvents and solvent effects in Organic Chemistry. In Ch. Reichardt (Ed.), Empirical parameters of solvent polarity (pp. 389-469). Wiley.

58. Watcher, M. P., Adams, R. E., Cotter, M. A., \& Settepani, J. A. (1979). Lumi-mestranol and epi-lumi-mestrano. Steroids, 33, 287-294.

59. Trudeau, V. L., Heyne, B., Blais, J. M., Temussi, F., Atkinson, S. K., Pakdel, F., Popesku, J. T., Marlatt, V. L., Scaiano, J. C., Previtera, L., \& Lean, D. R. S. (2012). Lumiestrone is photochemically derived from estrone and may be released to the environment without detection. Frontiers in Endocrinology. https://doi.org/10. 3389/fendo.2011.00083

60. Whidbey, Ch. M., Daumit, K. E., Nguyen, T.-H., Ashworth, D. D., Davis, J. C. C., \& Latch, D. E. (2012). Photochemical induced changes of in vitro estrogenic activity of steroid hormones. Water Research, 46, 5287-5296.

61. Weller, A. (1956). Innermolekularer protonen übergang imangeregten zustand. Zeitscrift für Elektrochemie, 60, 1144-1147.

62. Goodman, J., \& Brus, L. E. (1978). Proton transfer and tautomerism in an excited state of methyl salicylate. Journal of the American Chemical Society, 100, 7472-7474.

63. Smith, K. K., \& Kaufman, K. J. (1978). Picosecond studies of intramolecular proton transfer. Journal of Physical Chemistry, 82, 2286-2291.

64. Acuña, A. U., Armat Guerri, F., Catalán, J., \& González-Tablas, F. (1980). Dual fluorescence and ground state equilibriums in methyl salicylate, methyl 3-chlorosalicylate, and methyl 3-tertbutylsalicylate. Journal of Physical Chemistry, 84, 629-631.

65. Formosinho, S. J., \& Arnaut, L. G. (1993). Excited-state proton transfer reactions II. Intramolecular reactions. Journal of Photochemistry and Photobiology A: Chemistry, 75, 21-48.

66. Matsushima, R., \& Kageyama, H. (1985). Photochemical cyclization of 2'-hydroxychalcones. Journal of the Chemical Society, Perkin Transactions, II, 743-748.

67. Kaneda, K., \& Arai, T. (2003). Photoinduced hydrogen atom transfer in trans-1-(1'-hydroxy-2'-naphthyl)-3-(1-naphthyl)-2-propen-1-one. Photochemical \& Photobiological Sciences, 2, 402-406.

68. Kaneda, K., \& Arai, T. (2003). Mechanistic approach to the cyclization reaction of a 2'-hydroxychalcone analogue with light and solvent. Organic \& Biomolecular Chemistry, 1, 2041-2043.

69. Wu, Z.-Z., Nash, J., \& Morrison, H. (1992). Antenna-initiated photochemistry in polyfunctional steroids. Photoepimerization of $3 \alpha$-(dimethylphenylsilyloxy)-5 $\alpha$-androstane-6,17-dione and its $3 \beta$-isomer by through-bond exchange energy transfer. Journal of the American Chemical Society, 114, 6640-6648.

70. Perez, R. L., \& Escandar, G. M. (2013). Spectrofluorimetric study of estrogen-cyclodextrin inclusion complexes in aqueous systems. The Analyst, 138, 1239-1248.

71. Gañan, J., Morante-Zarcero, S., \& Sierra, I. (2014). Influence of organic modifier additives to separate steroids by micellar electrokinetic chromatography: Determination of the solute-micelle association constants at different acetonitrile concentrations. Analytical Letters, 47, 1513-1527.

72. Shakalisava, Y., \& Regan, F. (2006). Determination of association constants of inclusion complexes of steroids hormones and cyclodextrins from their electrophoretic mobility. Electrophoresis, 27, 3048-3056.

73. Luning Prak, D. J., Jahraus, W. I., Sims, J. M., \& Roy McArthur, A. H. (2011). An ${ }^{1} \mathrm{H}$ NMR investigation into the loci of solubilization of 4-nitrotoluene, 2,6-dinitrotoluene, and 2,4,6-trinitrotoluene in nonionic surfactant micelles. Colloids Surfaces A, 375, 12-22.

74. Bernardez, L. A. (2008). Investigation on the locus of solubilization of polycyclic aromatic hydrocarbons in non-ionic surfactant micelles with ${ }^{1} \mathrm{H}$ NMR spectroscopy. Colloids and Surfaces $A$, 324, 71-78.

75. Eriksson, J. C. (1963). NMR-experiments on solubilization in soap micelles. Acta Chemica Scandinavica, 17, 1478-1481.

76. Eriksson, J. C., \& Gillberg, G. (1966). NMR-studies of the solubilisation of aromatic compounds in cetyltrimethylammonium bromide solution. II. Acta Chemica Scandinavica, 20, 2019-2027.

77. Yuan, H. Z., Zhao, S., Cheng, G. Z., Zhang, L., Miao, X. J., Mao, S. Z., Yu, J. Y., Shen, L. F., \& Du, Y. R. (2001). Mixed micelles of Triton $\mathrm{X}-100$ and Cetyl triammonium bromide in aqueous solution studied by ${ }^{1} \mathrm{H}$ NMR. The Journal of Physical Chemistry B, 105, 4611-4615.

78. Gilard, V., Balayssac, S., Malet-Martino, M., \& Martino, R. (2010). Quality control of herbal medicines assessed by NMR. Current Pharmaceutical Analysis, 6, 234-245.

79. Wu, M., Wu, Z., Ding, S., Chen, Z., \& Cui, X. (2020). Different submicellar solubilization mechanisms revealed by ${ }^{1} \mathrm{H}$ NMR and 2D diffusion ordered spectroscopy (DOSY). Physical Chemistry Chemical Physics: PCCP, 22, 11075-11085.

80. Awad, T. S., Asker, D., \& Romsted, L. S. (2018). Evidence of coexisting microemulsion droplets in oil-in-water emulsions revealed by 2D DOSY ${ }^{1} \mathrm{H}$ NMR. Journal of colloid and interface science, 514, 83-92.

81. Weinreb, A., \& Werner, A. (1974). On the luminescence of estrogens. Photochemistry and Photobiology, 20, 313-321.

82. Butenandt, A., \& Poschmann, L. (1944). Uber lumiandrosteron. Berichte der deutschen chemischen Gesellschaft (A and B Series) , 77, 394-397.

83. Wherli, H., \& Schaffner, K. (1962). Photochemischereaktionen. Helvetica Chimica Acta, 45, 385-389.

84. Quinkert, G., \& Heine, H. G. (1963). Bildung unge sättigter carbonsäuren durchlicht induzierte autoxidation nicht konjugierter ketone. Tetrahedron Letters, 4, 1659-1664.

85. Wagner, P. J. (1976). Chemistry of excited triplet organic carbonyl compounds. Topics in Current Chemistry, 66, 1-52. 


\section{Authors and Affiliations}

\section{Matías I. Quindt ${ }^{1,2} \cdot$ Gabriel F. Gola $^{1,3} \cdot$ J. A. Ramirez ${ }^{1,3} \cdot$ Sergio M. Bonesi ${ }^{1,2}$ (])}

1 Departamento de Química Orgánica, Facultad de Ciencias Exactas Y Naturales, Universidad de Buenos Aires, Ciudad Universitaria, C1428EGA Buenos Aires, Argentina

2 Centro de Investigaciones en Hidratos de Carbono (CIHIDECAR), CONICET, Universidad de Buenos Aires, Ciudad Universitaria, C1428EGA Buenos Aires, Argentina
3 Unidad de Microanálisis Y Métodos Físicos Aplicados a Química Orgánica (UMYMFOR), CONICET,

Universidad de Buenos Aires, Ciudad Universitaria, C1428EGA Buenos Aires, Argentina 